\title{
Frontocingulate Dysfunction in Depression: Toward Biomarkers of Treatment Response
}

\author{
Diego A Pizzagalli; ${ }^{*, 1}$ \\ ${ }^{1}$ Center for Depression, Anxiety, and Stress Research \& Neuroimaging Center, McLean Hospital, Harvard Medical School, \\ Belmont, MA, USA
}

\begin{abstract}
Increased rostral anterior cingulate cortex ( $\mathrm{rACC}$ ) activity has emerged as a promising predictor of treatment response in depression, but neither the reliability of this relationship nor the mechanisms supporting it have been thoroughly investigated. This review takes a three-pronged approach to these issues. First, I present a meta-analysis demonstrating that the relationship between resting rACC activity and treatment response is robust. Second, I propose that the rACC plays a key role in treatment outcome because of its 'hub' position in the default network. Specifically, I hypothesize that elevated resting rACC activity confers better treatment outcomes by fostering adaptive self-referential processing and by helping to recalibrate relationships between the default network and a 'task-positive network' that comprises dorsolateral prefrontal and dorsal cingulate regions implicated in cognitive control. Third, I support this hypothesis by reviewing neuropsychological, electrophysiological, and neuroimaging data on frontocingulate dysfunction in depression. The review ends with a discussion of the limitations of current work and future directions.
\end{abstract}

Neuropsychopharmacology Reviews (2011) 36, 183-206; doi: I 0. I 038/npp.20 I0. I66; published online 22 September 2010

Keywords: biomarkers; depression; rostral anterior cingulate cortex; rumination; emotional biases; emotion regulation

\section{INTRODUCTION}

Major depressive disorder (MDD) is common, recurrent, and disabling. According to the World Health Organization, MDD is the third leading cause of global disease burden and a leading cause of disability worldwide (World Health Organization, 2008). In the United States, $16.6 \%$ of individuals will meet criteria for MDD at least once in their life (Kessler et al, 2005). In addition to profound personal suffering, MDD is associated with significant impairments in social and occupational functioning (Lopez et al, 2006) and places a staggering economic burden on society. For example, in the United States alone, workplace-related costs linked to depression have been estimated to exceed 50 billion dollars each year (Greenberg et al, 2003).

Despite the availability of a variety of treatments, up to $40-50 \%$ of patients fail to respond to antidepressant medication (eg, Trivedi et al, 2006) or psychological

${ }^{\star}$ Correspondence: Professor DA Pizzagalli, Harvard Medical School, Center for Depression, Anxiety, and Stress Research \& Neuroimaging Center, McLean Hospital, 115 Mill Street, Belmont, MA 02478, USA, Tel: +617 855-4230, Fax: +617 855-4231, E-mail: dap@mclean. harvard.edu

Received 7 July 2010; revised 21 August 2010; accepted 21 August 2010 treatment (eg, cognitive behavioral therapy; DeRubeis et al, 2005). The likelihood of remission (ie, complete recovery) is even lower. For example, only one in three patients achieved remission in the nationally representative Sequenced Treatment Alternatives to Relieve Depression $\left(\mathrm{STAR}^{\star} \mathrm{D}\right)$ study (Trivedi et al, 2006). For those achieving remission, up to $40 \%$ will relapse within 2 years (Boland and Keller, 2009). Unfortunately, attempts to identify clinical, sociodemographic, or biological variables predicting treatment response have met with very limited success (eg, Bagby et al, 2002; Nierenberg, 2003). Clearly, a better understanding of treatment mechanisms and identification of reliable predictors of treatment response would constitute major progress in the battle against depression.

In 1997, Mayberg and colleagues reported that increased resting glucose metabolism in the rostral anterior cingulate cortex (rACC; Brodmann area 24a/b) before the onset of pharmacological treatment predicted better treatment response in MDD (Mayberg et al, 1997), extending earlier reports of a link between increased resting rACC perfusion/ metabolism and antidepressant response to sleep deprivation (Ebert et al, 1991; Wu et al, 1992). Despite these promising findings, no systematic analysis has been performed to quantify the strength and reliability of the relationship between pre-treatment rACC activity and 
antidepressant response. Furthermore, in spite of numerous replications, the reason for the existence of this particular relationship remains poorly understood, and few attempts have been made to integrate this finding with the larger experimental and neuroimaging literature on depression.

The current review is organized around three goals designed to address these limitations. The first goal is to perform a meta-analysis to evaluate the strength of the link between resting rACC activity and treatment response (for rACC anatomical details, as well as differentiation between the rACC and other ACC subdivisions implicated in MDD, see Box 1). The second goal is to advance hypotheses concerning psychological and neurobiological mechanisms that might explain this link. In this context, I summarize emerging evidence indicating that the rACC represents one of the main 'hubs' within the default network (DN), an intrinsically organized functional network that has been associated with a variety of self-referential processes, including introspective processing, remembering the past, and planning the future (Buckner et al, 2008; Raichle et al, 2001). I argue that elevated resting rACC activity might foster better treatment outcome through (1) adaptive forms of reflective, self-focused processing and (2) adaptive interactions between the default network and a second network, the task-positive network, which includes dorsolateral prefrontal cortex (DLPFC) and dorsal ACC (dACC; eg, caudal area $24^{\prime}$ and $32^{\prime}$ ) regions that become activated during tasks requiring cognitive and attentional control. In light of this network-based conceptualization of depression, the third goal is to review neuropsychological, functional, and structural neuroimaging work that has probed frontocingulate pathways in depression. Based on these data, I suggest that frontocingulate dysfunction contributes to key cognitive and affective abnormalities in depression, including maladaptive ruminative tendencies, difficulty in disengaging from and inhibiting negative information, and emotion dysregulation. The review ends with a discussion of the limitations of current work and identification of future directions.

\section{META-ANALYSIS OF ROSTRAL ACC ACTIVITY AS A PREDICTOR OF ANTIDEPRESSANT TREATMENT RESPONSE}

\section{Study Sources}

Computerized searches using the databases PubMED, Cochrane Library, and PsycINFO were performed to identify neuroimaging studies that investigated predictors of treatment response. Several antidepressant treatments were considered, including pharmacology, electroconvulsive therapy (ECT), rapid transcranial magnetic stimulation (rTMS), sleep deprivation, and psychotherapy (eg, cognitive behavior therapy). Similarly, multiple imaging modalities were considered, including electroencephalogram/magnetoencephalogram (EEG/MEG), functional magnetic resonance imaging (fMRI), positron emission tomography
(PET), and single photon emission computed tomography (SPECT). Keyword combinations used in the search included ' $\mathrm{AMRI}$ OR PET OR SPECT OR EEG OR MEG AND depression AND antidepressant' and 'neuroimaging AND depression.' Abstracts of all articles were reviewed with respect to inclusion criteria (see below). Reference lists of relevant articles were checked to identify additional studies that might be relevant.

\section{Study Selection}

In all, 70 empirical studies were identified as candidates for the meta-analysis. Studies were included if they: (1) included individuals with unipolar depression (but not other mood disorders); (2) measured brain activity before the onset of antidepressant treatment; (3) included a standardized treatment; (4) directly compared eventual responders and nonresponders in their pre-treatment activity or evaluated correlations between pre-treatment activity and pre-to-post changes in depression severity; (5) used voxel-based or regions-of-interest analyses that allowed identification of ACC regions; (6) reported sufficient data to compute an effect size (means, standard deviations, $p$-values, F-values, or $r$ values); and (7) were published in English, German, or Italian. Medication status at the pre-treatment neuroimaging assessment was not constrained.

Based on these criteria, 3 studies were excluded because they included individuals with bipolar disorder (Benedetti et al, 2007; Ketter et al, 1999; Speer et al, 2009); 4 studies were excluded because the first neuroimaging assessment occurred after treatment onset (Brockmann et al, 2009; Conway et al, 2006; Joe et al, 2006; Keedwell et al, 2009); 1 study was excluded because no standardized treatment was provided (Halloran et al, 1999); 26 studies were excluded because no direct pre-treatment comparison between eventual responders and nonresponders or correlation between pre-treatment activity and pre-to-post changes in depression severity was performed (Aihara et al, 2007; Awata et al, 1998, 2002; Bench et al, 1995; Brody et al, 2001; Brunovsky et al, 2006; Buchsbaum et al, 1997; Davies et al, 2003; Goodwin et al, 1993; Henry et al, 2001; Holthoff et al, 2004; Hornig et al, 1997; Ishizaki et al, 2008; Kennedy et al, 2001, 2007; Kito et al, 2008a; Kohn et al, 2007; Mayberg et al, 2000, 2002; Nobler et al, 2001; Robertson et al, 2007; Scott et al, 1994; Segawa et al, 2006; Smith et al, 1999, 2009; Vlassenko et al, 2004); 1 study was excluded because no region-of-interest or voxel-based analyses were performed to allow for a clear delineation of brain regions associated with treatment response (Navarro et al, 2004); 6 studies were excluded because no information was reported to permit computation of effect sizes pertaining to ACC regions (Costafreda et al, 2009b; Little et al, 2005; Marquand et al, 2008; Milak et al, 2009; Siegle et al, 2006; Teneback et al, 1999); 5 studies were excluded because they presented a partial or full reanalysis of a prior study (Clark et al, 2006; Keedwell et al, 
Box 1 Anterior cingulate cortex anatomy and relevance to depression

Depression has been associated with dysfunction in various ACC regions. In addition to the link between increased rACC and better treatment response, hyperactivity in subgenual ACC regions (Mayberg, 2003) but hypoactivity in dorsal ACC (dACC) regions (Davidson et al, 2002) have been generally described in MDD. Anatomically, the rACC (often referred to in the literature as 'pregenual' or 'perigenual') is located anterior to the genu, and includes Brodmann area (BA) 32 and inferior parts of BA24 (eg, Vogt et al, 1995; see Figure I). The subgenual ACC is located underneath the genu of the corpus callosum and corresponds mainly to BA25 and caudal portions of BA32 and BA24. Finally, the $\mathrm{dACC}$ includes caudal area $24^{\prime}$ and $32^{\prime}$, and cingulate motor area.

The complex pattern of findings in MDD likely reflects the fact that in terms of function, cytology, and receptor architecture, the ACC is highly heterogeneous (eg, Devinsky et al, 1995; Palomero-Gallagher et al, 2008; Vogt et al, 2005). In general, an 'affect subdivision' encompassing rACC and subgenual areas and a dorsal 'cognitive subdivision' of the ACC (dACC) have been distinguished (Devinsky et al, 1995). By virtue of strong connections with limbic and paralimbic structures (amygdala, nucleus accumbens, orbitofrontal cortex, periaqueductal grey, and autonomic brainstem motor nuclei), the affective subdivision has been found to play key roles in regulating visceral and autonomic responses to stressful events, assigning emotional valence to internal and external stimuli, and emotional expression. The cognitive subdivision, on the other hand, shows strong connections with DLPFC regions, supplementary motor areas, parietal cortex, and spinal cord and has been implicated in response selection and processing of cognitively demanding information (Figure I).

Recent studies have further highlighted that the rACC and subgenual ACC (BA25) differ in terms of anatomical connectivity, cytology, and neurotransmitter receptor organization (Johansen-Berg et al, 2008; Palomero-Gallagher et al, 2008). Although a full discussion of these data is beyond the scope of this review, it is important to emphasize that the rACC has stronger connection with the medial prefrontal and AACC regions, whereas the subgenual ACC shows stronger connections with the OFC, nucleus accumbens, amygdala, hippocampus, and hypothalamus (Johansen-Berg et al, 2008; Chiba et al, 200 I). In virtue of these anatomical connections, it has been suggested that normalization of subgenual ACC (BA 25) hyperactivity — which might be linked in MDD to dysregulation in sleep, appetite, libido, and endocrine function and regulation of negative affect -is a prerequisite for symptom remission (Mayberg, 2003). In this review, it is argued that elevated resting $\mathrm{rACC}$ activity increases the likelihood of treatment response by fostering adaptive self-referential processing and by helping to recalibrate relationships between the default network and a 'task-positive network' that comprises DLPFC and dACC regions that implement cognitive control.

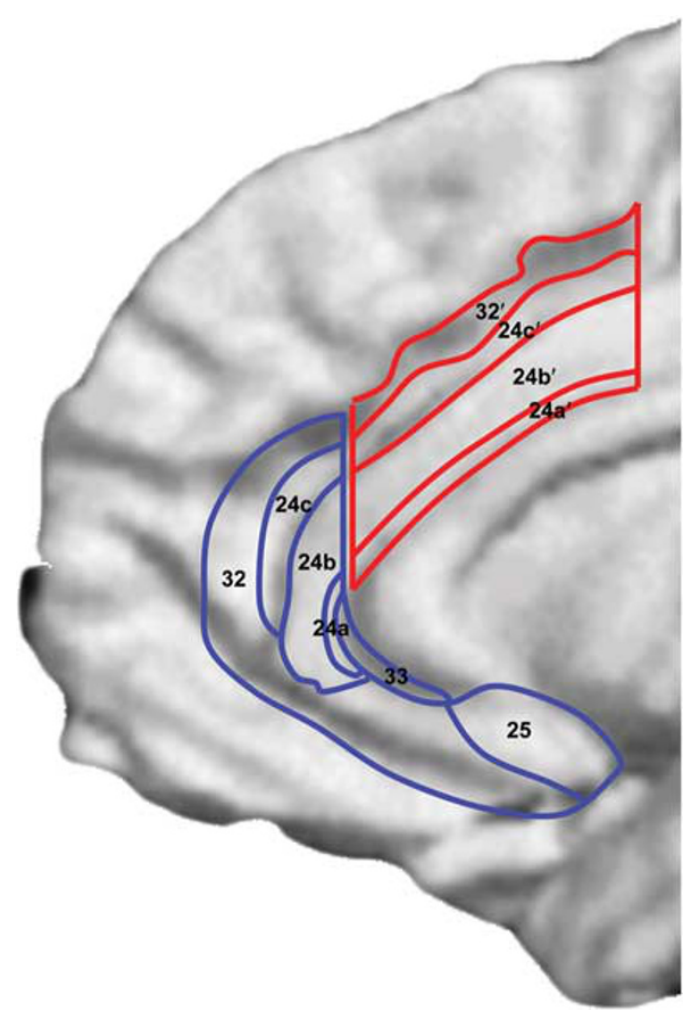

Figure I. Schematic representation of ACC cytoarchitectural areas displayed on an inflated, medial cortical surface. Affective and cognitive ACC subdivisions are highlighted in blue and red, respectively (Reprinted from Bush et al, 2000; with permission from Elsevier).

2010; Mulert et al, 2007b; Seminowicz et al, 2004; Smith et al, 2002); and finally, 1 study was excluded because of a small sample size that precluded statistical analyses $(n=3$; Clark et al, 2001).

The remaining 23 studies were entered in the metaanalysis (Table 1). For each study, only one statistical test contributed to the analyses. In order to standardize the effect sizes across studies, Cohen's $d$ was calculated. For most of the studies, the mean pre-treatment rACC signal for eventual nonresponders was subtracted from the mean pretreatment rACC signal for eventual responders, and the difference was divided by the pooled standard deviation. In cases where means and standard deviations were unavailable, d-values were calculated from exact $r$-, $p$-, $t$-, or F-values using standard formulae (Wolf, 1986). In eight cases, a $d$-value was computed from the correlation between 
TABLE 1. Summary of Neuroimaging Studies Investigating rACC Activity as a Predictor of Treatment Response in MDD Subjects

\begin{tabular}{|c|c|c|c|c|c|c|}
\hline Treatment & Study & Imaging & Task & Numbers of subjects & $\begin{array}{l}\text { Increased pre- } \\
\text { treatment rACC } \\
\text { in responders }\end{array}$ & $\begin{array}{l}\text { Effect size } \\
\text { (Cohen's d) }\end{array}$ \\
\hline \multicolumn{7}{|l|}{ Pharmacology } \\
\hline Various $A D$ & *Mayberg et al, 1997 & PET & Resting & 8 Resp. vs 10 Non-Resp. & $x^{a}$ & 1.43 \\
\hline Paroxetine & ${ }^{*}$ Brody et al,1999 & PET & Resting & 9 Resp. vs 7 Non-Resp. & Reversed finding & -1.20 \\
\hline Nortriptyline & *Pizzagalli et al, 2001 & EEG & Resting & 9 Resp. vs 9 Non-Resp. & $x$ & 1.43 \\
\hline Paroxetine & *Saxena et al, 2003 & PET & Resting & $44 \mathrm{MDD}$ subjects & $x^{b}$ & 0.80 \\
\hline Venlafaxine & ${ }^{*}$ Davidson et al, 2003 & fMRI & Picture processing & 12 MDD subjects & $x^{b}$ & 1.04 \\
\hline $\begin{array}{c}\text { Bupropion or } \\
\text { Venlafaxine }\end{array}$ & Little et al, 2005 & PET & Attentional task & 13 Resp. vs 27 Non-Resp & Null finding ${ }^{C}$ & Not available \\
\hline $\begin{array}{l}\text { Citalopram or } \\
\text { Reboxetine }\end{array}$ & ${ }^{*}$ Mulert et al, 2007a & EEG & Resting & 10 Resp. vs 10 Non-Resp. & $x$ & 1.33 \\
\hline Fluoxetine & ${ }^{*}$ Chen et al, 2007 & fMRI & Face perception & 16 MDD subjects & $x^{b}$ & 2.34 \\
\hline Escitalopram & *Langenecker et al, 2007 & fMRI & Go/NoGo & 15 MDD subjects & $x^{b}$ & 1.23 \\
\hline $\begin{array}{l}\text { Venlafaxine } \\
\text { (or CBT) }\end{array}$ & *Konarski et al, 2009 & PET & Resting & 16 Resp. vs 8 Non-Resp. & Reversed finding & -1.49 \\
\hline Paroxetine & Milak et al, 2009 & PET & Resting & 11 Resp. vs 22 Non-Resp & Null finding ${ }^{C}$ & Not available \\
\hline $\begin{array}{c}\text { Fluoxetine or } \\
\text { Venlafaxine }\end{array}$ & *Korb et al, 2009 & EEG & Resting & 22 Resp. vs 15 Non-Resp. & $x$ & 0.70 \\
\hline Ketamine & ${ }^{*}$ Salvadore et al, 2009 & MEG & Face perception & $11 \mathrm{MDD}$ subjects & $x^{b}$ & 2.27 \\
\hline \multicolumn{7}{|c|}{ Sleep deprivation } \\
\hline Total SD & ${ }^{*}$ Ebert et al, 1991 & SPECT & Resting & 5 Resp. vs 3 Non-Resp. & $x$ & 2.46 \\
\hline Total SD & *Wu et al, 1992 & PET & Attentional task & 4 Resp. vs 11 Non-Resp. & $x^{d}$ & 1.35 \\
\hline Total SD & ${ }^{*}$ Ebert et al, 1994 & SPECT & Resting & 11 Resp. vs 9 Non-Resp. & $x$ & 1.92 \\
\hline Partial SD & *Volk et al, 1997 & SPECT & Resting & 9 Resp. vs 6 Non-Resp. & $x^{e}$ & 0.61 \\
\hline Total SD & *Wu et al, 1999 & PET & Resting & 12 Resp. vs 24 Non-Resp. & $x$ & 0.87 \\
\hline Total SD & *Holthoff et al, 1999 & SPECT & Resting & 8 Resp. vs 6 Non-Resp. & $\mathrm{x}$ & 3.80 \\
\hline Partial SD & ${ }^{*}$ Clark et al, 2006 & fMRI & Resting & 5 Resp. vs 12 Non-Resp. & $\mathrm{x}$ & 1.14 \\
\hline \multicolumn{7}{|c|}{$E C T$} \\
\hline & ${ }^{*}$ McCormick et al, 2007 & PET & Resting & 5 Resp. vs 5 Non-Resp. & Reversed finding & -1.77 \\
\hline \multicolumn{7}{|l|}{ rTMS } \\
\hline & Teneback et al, 1999 & SPECT & Resting & 6 Resp. vs 6 Non-Resp. & Null finding ${ }^{\mathrm{C}}$ & Not available \\
\hline & *Mottaghy et al, 2002 & SPECT & Resting & 17 MDD subjects & Reversed finding ${ }^{b}$ & -1.37 \\
\hline & ${ }^{*}$ Nadeau et al, 2002 & SPECT & Attentional task & 8 MDD subjects & $x^{b}$ & 1.46 \\
\hline & *Langguth et al, 2007 & SPECT & Resting & 24 MDD subjects & $x^{b}$ & 1.01 \\
\hline & ${ }^{*}$ Kito et al, 2008b & SPECT & Resting & 6 Resp. vs 8 Non-Resp. & $X$ & 1.96 \\
\hline \multicolumn{7}{|l|}{ CBT } \\
\hline & Siegle et al, 2006 & fMRI & Self-referential task & 14 MDD subjects & Null finding ${ }^{\mathrm{C}}$ & Not available \\
\hline
\end{tabular}

Abbreviation: Resp., responders; Non-Resp., non-responders.

aHypothesized pattern was observed.

${ }^{b}$ Refers to a correlation between pre-treatment rACC activity and changes in depression severity.

${ }^{\mathrm{C}}$ Not included in the meta-analysis (no information was provided allowing the computation of effect sizes pertaining to ACC regions).

'Effect size for an aggregate 'limbic system' (ACC, amygdala, and hippocampus).

'Effect size for an aggregate region (OFC and 'basal ACC').

${ }^{*}$ Included in the meta-analysis.

pre-treatment rACC signal and pre-to-post changes in depression severity (Chen et al, 2007; Davidson et al, 2003; Langenecker et al, 2007; Langguth et al, 2007; Mottaghy et al, 2002; Nadeau et al, 2002; Salvadore et al, 2009; Saxena et al, 2003). Next, a combined (weighted) effect size across all studies was computed using a randomeffects model implemented in the statistical package Comprehensive Meta-analysis V2 (Borenstein and Rothstein, 1999); this yielded a $Z$-value that was tested against the null hypothesis of $d=0.00$. Based on prior recommendations (Cohen, 1988), $d$ values $<0.2$, between 0.4 and 0.6 , and $>0.8$ were regarded as representing small, moderate, and large effects, respectively.

A homogeneity test (Cochran's Q test) evaluated whether the studies shared a common population effect size. Finally, to explore the possibility of publication bias (ie, bias toward non-publication of studies with no effects), Orwin's FailSafe Number of studies test was performed (Orwin, 1983; Rosenthal, 1991). The Fail-Safe Number reflects the number of unpublished studies required to reduce the observed effect size to a negligible level, and is computed as:

Fail-Safe Number $=\mathrm{k} *\left[\left(\mathrm{ES}_{k} / \mathrm{Es}_{\mathrm{c}}\right)-1\right]$

where $\mathrm{k}$ is the number of studies $(n=23), \mathrm{ES}_{k}$ is the mean weighted effect size, and $\mathrm{Es}_{\mathrm{c}}$ is the criterion effect size (Lipsey and Wilson, 2001; Orwin, 1983). In two separate analyses, $\mathrm{Es}_{\mathrm{c}}$ was set to 0.10 and 0.20 . 


\section{Results}

The 23 studies included in the meta-analysis yielded a total sample of 426 MDD subjects (Table 1). A random-effects analysis comparing pre-treatment mean rACC activity between eventual responders $(n=136)$ and nonresponders $(n=143) \quad(15$ studies $)$ or considering the correlation between pre-treatment rACC signal and pre-to-post changes in depression severity ( 8 studies; $n=147$ ) indicated that the mean weighted effect size was 0.918 (95\% confidence interval 0.442-1.393; $Z=3.782, p<0.00017$ ), reflecting a large effect. [In light of recent controversy concerning possible overestimates of brain-behavior relationships in correlational analyses of neuroimaging data (Vul et al, 2009; but see Lieberman et al, 2009; Nichols and Poline, 2009; Poldrack and Mumford, 2009), effect sizes emerging from the 8 studies reporting correlations between pre-treatment rACC signal and pre-to-post changes in depression severity were compared with those emerging from the remaining 15 non-correlational studies. The mean effect sizes were similar (1.098 \pm 1.115 vs $0.969 \pm 1.496)$ and statistically indistinguishable $(\mathrm{t}(21)=0.211, p=0.84)$. Based on this finding, and the fact that some of the studies implemented statistically independent analyses (eg, the rACC was anatomically defined; Langguth et al, 2007; Nadeau et al, 2002) or did not use whole-brain corrrelational analyses to identify supra-threshold clusters (eg, Davidson et al, 2003; Salvadore et al, 2009), the mean weighted effect size emerging from the current meta-analysis was interpreted as representing a reliable estimate of the link between rACC activity and treatment response.] Of the 23 studies, 19 found an association between increased pre-treatment rACC activity and eventual treatment response, whereas 4 found an association between low pre-treatment rACC activity and better response. Orwin's Fail-Safe Number test indicated that 160 unpublished studies with null effects would be required to reduce the observed effect size to a negligible level $(d=0.10 ; 69$ null results would be required to reduce the effect size to $d=0.20$ ). Cochran's $\mathrm{Q}$ test was also significant $(\mathrm{Q}=92.93, \mathrm{df}=22, p<0.001)$, indicating heterogeneity of study effect sizes. Thus, separate meta-analyses were computed for each treatment modality (pharmacology, ECT, rTMS, sleep deprivation), imaging modality (EEG/ MEG, fMRI, PET, SPECT), and medication status at pretreatment assessment (medicated, unmedicated). As summarized in Table 2, all effects were significant and in the moderate-large range with the exception of a highly significant negative effect size for ECT, which was because of a single negative finding (McCormick et al, 2007). Thus, the finding of higher pre-treatment rACC activity predicting better treatment response generalizes to different treatments (with the exception of ECT), assessment methods, and medication status. In the following, a brief summary of these findings is provided.

Sleep Deprivation (SD). Ebert et al (1991) were the first to report that eventual responders to SD had increased pretreatment rACC perfusion, which normalized after successful treatment (see also Ebert et al, 1994). Increased pretreatment rACC activity in eventual responders to SD has been replicated with SPECT (Holthoff et al, 1999; Volk et al, 1997) and PET (Wu et al, 1992, 1999). Similarly, normalization of rACC activity after SD has been confirmed in four additional studies (Smith et al, 1999; Volk et al, 1997; Wu et al, 1992, 1999). In Volk et al (1997), pre-treatment cingulate perfusion was correlated with post-SD decreases in depression severity $(r=0.77)$. More recently, using arterial spin labeling, Clark et al (2006) found that MDD

TABLE 2. Meta-Analyses of Links Between Increased Pre-Treatment rACC Activity and Treatment Response for (a) All Studies, and for Studies Split Based on (b) Treatment Modality, (c) Imaging Modality, and (d) Pre-Treatment Medication Status

\begin{tabular}{|c|c|c|c|c|c|}
\hline Analysis & $\begin{array}{c}\text { Mean weighted } \\
\text { effect size }\end{array}$ & $\begin{array}{c}95 \% \\
\mathrm{Cl} \\
\end{array}$ & $\begin{array}{c}\text { Number of } \\
\text { studies }\end{array}$ & $\begin{array}{c}\mathrm{Z} \\
\text { value }\end{array}$ & $\begin{array}{c}P \\
\text { value }\end{array}$ \\
\hline (a) Overall ${ }^{a}$ & 0.918 & 0.442 to 1.393 & 23 & 3.782 & 0.000016 \\
\hline \multicolumn{6}{|l|}{ (b) By treatment ${ }^{b}$} \\
\hline ECT & -1.773 & -3.173 to -0.374 & 1 & -2.484 & 0.013 \\
\hline Pharmacology & 0.674 & 0.391 to 0.958 & 11 & 4.659 & $<0.00001$ \\
\hline rTMS & 0.718 & 0.078 to 1.358 & 4 & 2.199 & 0.028 \\
\hline Sleep deprivation & 1.319 & 0.901 to 1.737 & 7 & 6.182 & $<0.00001$ \\
\hline \multicolumn{6}{|c|}{ (c) By imaging modality } \\
\hline EEG/MEG & 1.085 & 0.609 to 1.560 & 4 & 4.470 & $<0.00001$ \\
\hline fMRI & 1.350 & 0.658 to 2.041 & 4 & 3.827 & 0.00013 \\
\hline PET & 0.339 & 0.019 to 0.658 & 7 & 2.079 & 0.038 \\
\hline SPECT & 1.219 & 0.762 to 1.677 & 8 & 5.224 & $<0.00001$ \\
\hline \multicolumn{6}{|c|}{ (d) By medication status ${ }^{b}$} \\
\hline Medicated & 1.218 & 0.816 to 1.619 & 8 & 5.946 & $<0.00001$ \\
\hline Unmedicated & 0.619 & 0.360 to 0.878 & 15 & 4.679 & $<0.00001$ \\
\hline
\end{tabular}

Abbreviation: $\mathrm{Cl}$, confidence interval.

aRandom-effects model.

bFixed-effects model. 
subjects responding to partial SD had increased pretreatment perfusion in the ventral ACC and left rACC relative to nonresponders. In responders only, perfusion normalized (ie, decreased) after SD.

Pharmacology. In an influential paper, Mayberg et al (1997) observed that eight MDD patients who responded to various pharmacological treatments after 6 weeks showed higher pre-treatment resting rACC metabolism than both nonresponders $(n=10)$ and controls $(n=13)$ (Figure 1a). Relative to controls, nonresponders showed lower pretreatment rACC metabolism, indicating that blunted rACC activity predicted poor response. In a subsequent study from this group, MDD subjects demonstrated higher metabolic rates in the right rACC than controls (Cohen's $d=0.78$; Kennedy et al, 2001). As all MDD subjects showed at least a $50 \%$ reduction in Hamilton Rating Scale for Depression (HRSD) score after 6 weeks of paroxetine treatment, these data also highlight a link between rACC hyperactivity and response.

Measuring resting EEG data before an open-label trial with nortriptyline, we replicated these findings using a source localization technique (Pizzagalli et al, 2001; Figure 1b). Specifically, resting rACC activity in the theta frequency band $(6.5-8 \mathrm{~Hz})$ predicted degree of treatment response to nortriptyline 4-6 months later. It is noteworthy that this link emerged exclusively for the theta band, as there is evidence implicating the ACC in theta oscillations (Asada et al, 1999; Feenstra and Holsheimer, 1979; Pizzagalli et al, 2003). A recent re-analysis of these data revealed that a specific cutoff of pre-treatment rACC activity correctly classified $88.9 \%$ of eventual responders and $89.9 \%$ of eventual nonresponders, highlighting a promising sensitivity/specificity profile (DA Pizzagalli, unpublished observation). As in Holthoff et al (1999) and Mayberg et al (1997), the rACC was the only region differentiating eventual responders and nonresponders.

These findings were replicated in two additional studies that used the same EEG source localization technique. Taking a region-of-interest approach, Mulert et al (2007a) reported that in comparison to nonresponders, MDD subjects responding to either citalopram or reboxetine

Figure 1. Selected findings implicating the rACC in treatment response in MDD. (a) Mayberg et al (1997): Increased pre-treatment rACC metabolism in responders relative to nonresponders (yellow). This finding was replicated in a larger sample of 25 responders vs 20 nonresponders (Brannan et al, 2000) (see right panel). (b) Pizzagalli et al (2001): Increased pre-treatment resting $\mathrm{rACC}$ theta activity in responders relative to nonresponders (red). (c) Holthoff et al (2004): Decreased rACC rCBF with symptom remission (yellow). (d) Davidson et al (2003): Increased BOLD signal in the rACC in response to emotional pictures correlated with lower post-treatment depressive symptoms (yellow). (Modified with permission from Mayberg, 2003 (with permission by Oxford University Press), Pizzagalli et al, 2001 (with permission by American Psychiatric Associations), Holthoff et al, 2004 (with permission by John Wiley and Sons), and Davidson et al, 2003 (with permission by American Psychiatric Associations)). treatment had increased pre-treatment resting theta activity within the rACC. The effect size differentiating responders and nonresponders $(d=1.33)$ was similar to that in our

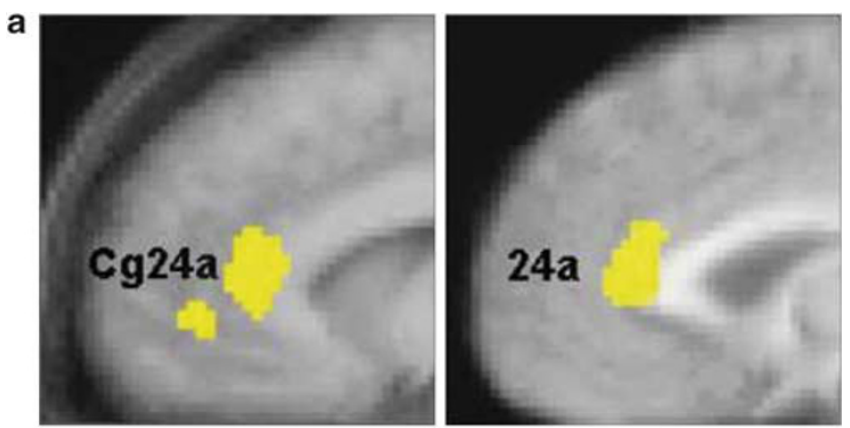

b

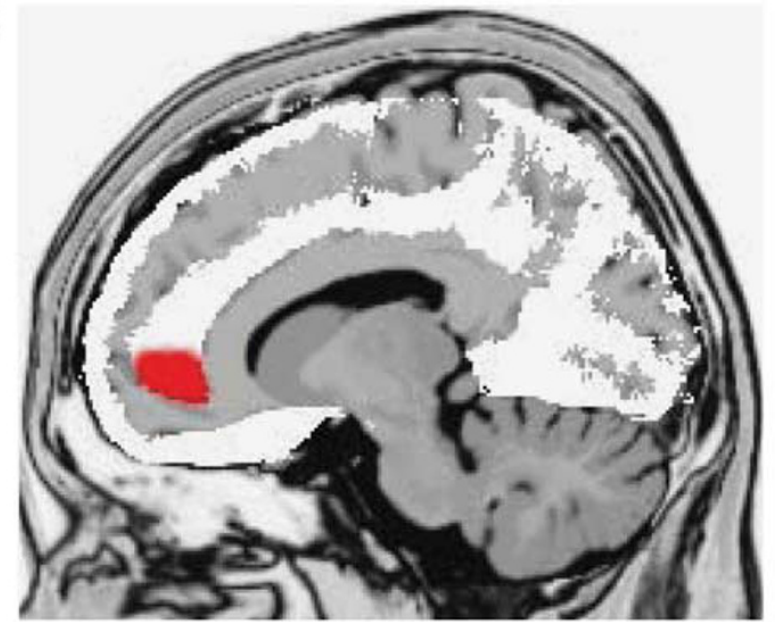

C

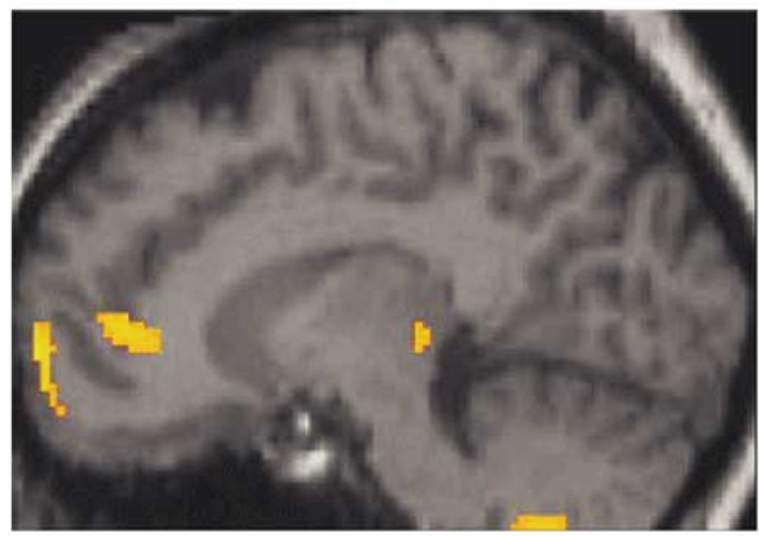

d

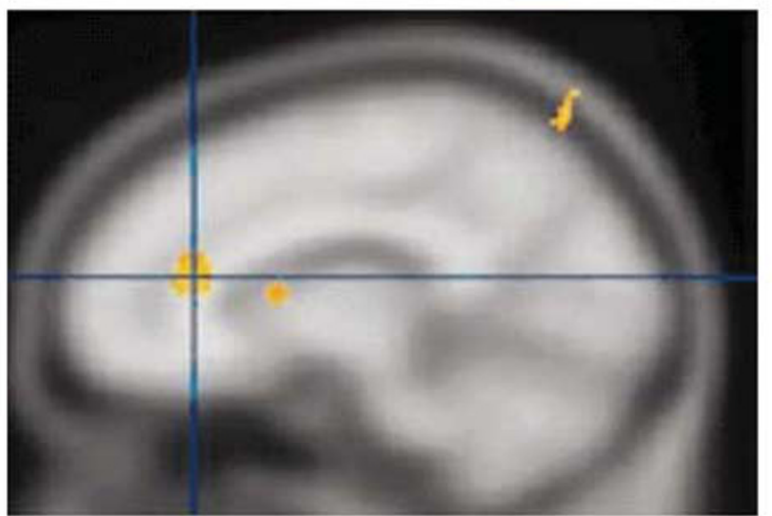


earlier report $(d=1.43)$. Moreover, in a placebo-controlled, double-blind study, Korb et al (2009) reported that drug responders had significantly higher resting theta current density in the rACC relative to nonresponders prior to treatment. Notably, findings were specific to drug responders and not placebo responders, and emerged when considering both a selective serotonin reuptake inhibitor (SSRI; fluoxetine) and a serotonin-norepinephrine reuptake inhibitor (SNRI; venlafaxine). Altogether, these findings suggest that the link between resting rACC theta activity and treatment response generalizes across antidepressant classes but does not extend to placebo response.

In an open-label PET study, Saxena et al (2003) reported a positive link between pre-treatment rACC/medial PFC metabolism and response to 8-12 weeks of paroxetine in a sample of MDD individuals, some of whom had comorbid obsessive compulsive disorder. Another PET study reported decreased rACC blood flow from baseline to remission after open-label treatment with citalopram or mirtazapine (Holthoff et al, 2004; Figure 1c). Because the second scan occurred after remission, this decrease is consistent with rACC normalization (no analyses focusing on pre-treatment predictors were performed).

Finally, a link between increased pre-treatment rACC activity and response to antidepressants has emerged from three studies in which participants were engaged in either passive observation of emotionally valenced stimuli or a response inhibition task. Davidson et al (2003) found that greater rACC activation to negative $v s$ neutral pictures correlated with fewer symptoms after 8 weeks of open-label venlafaxine treatment (Figure 1d). Similarly, Chen et al (2007) reported that a greater rACC response to increasing levels of sadness in facial stimuli predicted increasingly rapid responses to fluoxetine. Moreover, increased rACC activation to repeated presentation of fearful faces predicted a rapid (230-min post-administration) antidepressant response to ketamine, an $N$-methyl-D-aspartate receptor antagonist (Salvadore et al, 2009). Finally, increased rACC activation in response to commission errors in a GO/NOGO task predicted greater treatment response after a 10-week escitalopam trial ( $r=0.52$, S Langenecker, personal communication, 23 March 2010; Langenecker et al, 2007), although the region emerging from this study was anatomically superior and anterior to the pregenual rACC.

rTMS. Five studies have investigated the relationship between pre-treatment rACC activity and response to rTMS. In a small SPECT study $(n=7)$, Nadeau et al (2002) found that pre-treatment rACC blood flow was correlated with reduction in depression severity following 10 days of rTMS over the left DLPFC $(r=-0.59$, S Nadeau, personal communication, 28 March 2010). Similarly, increased pretreatment rACC activity was found to predict reduction of depressive symptoms in MDD patients on stable medication receiving a 2-week add-on rTMS treatment $(r=-0.49, \mathrm{~B}$ Langguth, personal communication, 23 March 2010; Langguth et al, 2007) or a 3-week low-frequency stimulation over the right DLPFC (Kito et al, 2008b). In contrast, Mottaghy et al (2002) found that lower pretreatment $\mathrm{rCBF}$ in the rACC was linked to greater rTMS response, whereas Teneback et al (1999) found no relationship between rACC and response to rTMS.

Additional findings. There is additional evidence supporting the proposed link between the rACC and antidepressant response. First, smaller rACC volume has been found to predict poor treatment response and more frequent hospitalization in depressed patients (Chen et al, 2007; Costafreda et al, 2009a; Frodl et al, 2008a; Gunning et al, 2009). Second, reduced magnetization transfer ratio-assumed to reflect reduced integrity of myelinated white matter - in the rACC has been associated with treatmentresistant depression (Zhang et al, 2009). Third, illness chronicity and refractoriness in late-life depression have been linked to decreased pre-treatment rACC activity, which persisted even after responding to ECT (Awata et al, 2002). In line with the hypothesis that sustained paralimbic hypoactivation during resting states predicts lack of antidepressant response, an earlier study from this group showed that subjects with refractory MDD had significantly lower PFC and ACC perfusion than nonrefractory subjects, who in turn displayed lower perfusion than healthy controls (Awata et al, 1998). Moreover, Kennedy et al (2007) reported that nonresponse to an 8week treatment with venlafaxine or CBT was associated with decreased metabolism in the rACC. Together, these findings suggest that a hypoactive rACC during resting states is a reliable biomarker of treatment nonresponsiveness in MDD.

Although the link between rACC hyperactivity and treatment response has been observed in 19 studies, it is important to mention two sets of inconsistencies. First, no pre-treatment rACC differences between responders and nonresponders emerged in four studies, which administered paroxetine (alone or in combination with other antidepressants) (Milak et al, 2009), buproprion or venlafaxine (Little et al, 2005), rTMS (Teneback et al, 1999), and CBT (Siegle et al, 2006). Second, a link between lower pretreatment rACC $\mathrm{rCBF}$ and greater antidepressant response to rTMS in treatment-resistant MDD patients (Mottaghy et al, 2002) and individuals with psychotic depression (McCormick et al, 2007) has been described. Similarly, Brody et al (1999) reported that lower pre-treatment ventral ACC (including rACC) metabolism correlated with greater reductions on the HRSD after paroxetine treatment. Moreover, Siegle et al (2006) found that decreased pre-treatment subgenual PFC (BA 25) and increased amygdalar activation during processing of negative words were linked to better CBT response (see also Konarski et al, 2009). Because the subgenual PFC has been implicated in regulating limbic activity, Siegle et al (2006) proposed that CBT might be most beneficial for patients characterized by increased emotional reactivity and deficient emotional regulation. These findings contrast with data linking increased pre-treatment subgenual PFC resting blood flow to citalopram response (Brockmann et al, 2009). 
Although these data appear inconsistent with the evidence emerging from the meta-analysis, it is important to emphasize that the subgenual and ventral ACC regions identified in these studies do not spatially overlap with the rACC, raising the possibility that different ACC subdivisions might be implicated in response depending on the treatment modality.

Summary. At least 19 studies have found that increased pre-treatment rACC activity predicts better antidepressant response. Among these studies, 13 probed rACC function during resting states, whereas the remaining 6 used relatively simple tasks (eg, passive observation of emotional pictures; but see Langenecker et al, 2007). The relationship between increased rACC activity and positive antidepressant response appears to be robust, as it emerged across treatments that included various drugs (eg, SSRIs, atypical antidepressants, ketamine), sleep deprivation, and rTMS, and has been replicated across imaging modalities (fMRI, PET, SPECT, EEG).

\section{THE ROSTRAL ACC AS A KEY HUB WITHIN THE DN}

\section{The DN}

The observed link between rACC resting activity and treatment response is interesting in light of evidence that the rACC is a hub in the DN. The DN comprises the vmPFC/ rACC, posterior cingulate, retrosplenial cortex, lateral parietal cortex, lateral temporal cortex, dorsal medial PFC, and hippocampal formation (eg, Buckner et al, 2008; Raichle et al, 2001; Figure 2). Activity and functional connectivity within the DN increases during resting states or when participants engage in internally focused tasks (Gusnard et al, 2001; Simpson et al, 2001). Conversely, DN regions consistently deactivate during processing of external stimuli (Shulman et al, 1997). As discussed in more detail below, these data have generally been interpreted as suggesting that resting DN activity reflects a variety of adaptive self-referential functions (Broyd et al, 2009; Buckner et al, 2008; Raichle et al, 2001), which might explain the link between increased resting rACC activity and better treatment outcome.

Providing insight into the possible functional significance of the $\mathrm{DN}$, reduced deactivation of $\mathrm{DN}$ regions, including the rACC, was reported in an early study in which participants attended to their affective responses to emotional pictures relative to physical aspects of the picture itself (Gusnard et al, 2001). Similar results have been obtained in more recent studies employing a variety of selfreferential tasks (eg, evaluating negative personality traits with respect to oneself; Schmitz and Johnson, 2006; van Buuren et al, 2010; Yoshimura et al, 2009; see Northoff et al, 2006 for a review). Notably, the level of rACC deactivation was negatively correlated with the extent to which pictures were judged as personally relevant: the more self-relevant

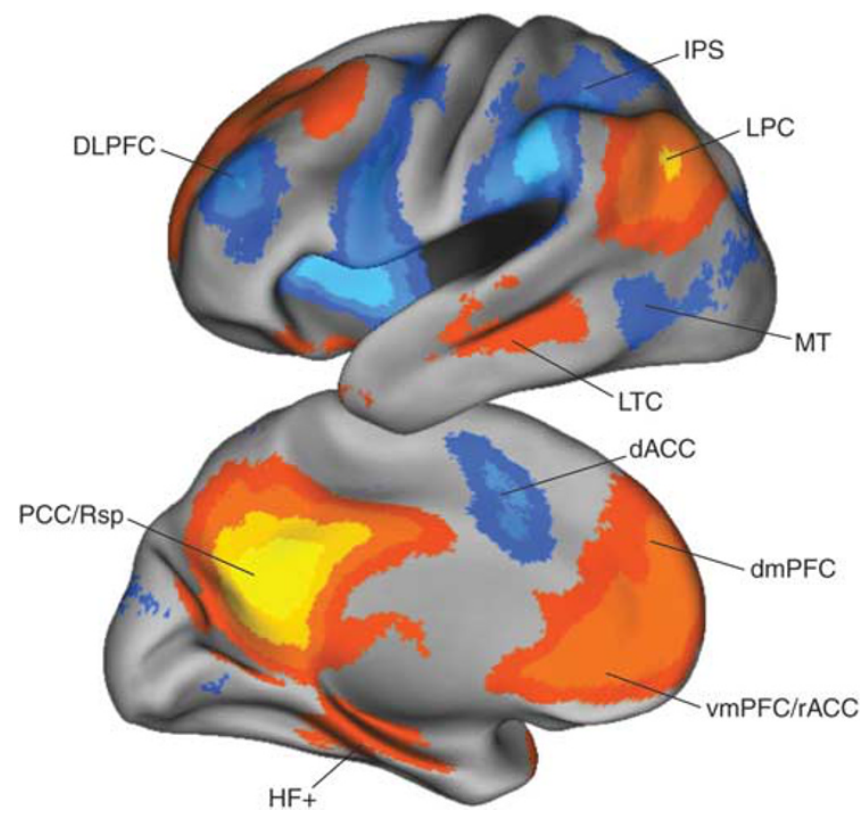

Figure 2. The default network (orange colors) includes regions that deactivate during processing of external stimuli, including the vmPFC/ rACC, posterior cingulate (PCC), retrosplenial cortex (Rsp), lateral parietal cortex (LPC), lateral temporal cortex (LTC), dorsal medial PFC (dmPFC), and hippocampal formation ( $\mathrm{HF}+$ ), which includes the entorhinal cortex and surrounding cortex (eg, parahippocampal cortex). The task-positive network (blue color) includes, among others, the DLPFC, dACC, intraparietal sulcus (IPS), and middle temporal (MT) area and becomes activated during tasks requiring cognitive and attentional control. Blue colors: regions that negatively correlate with the default network; red: regions that positively correlate with the default network. (Modified with permission from Buckner et al, 2008; with permission by John Wiley and Sons).

the pictures (as measured by participant ratings), the weaker the rACC deactivation (Phan et al, 2004). These findings are complemented by a report of increased functional connectivity between the rACC/ventromedial PFC (vmPFC) and a variety of limbic/paralimibic regions, including the amygdala and insula, when healthy participants related negative and positive traits to themselves $v s$ when they simply judged the valence of the stimuli (Schmitz and Johnson, 2006). These data suggest that increased resting rACC activity in treatment responders may be linked to adaptive forms of self-referential processing.

A critical point for the current review is that the DN appears to consist of two subsystems that converge on a midline core with two main hubs, the rACC and posterior cingulate cortex (Andrews-Hanna et al, 2010). The first subsystem, referred to as the medial temporal lobe system, includes the vmPFC, the retrosplenial cortex, and the hippocampus (among other regions). It is typically recruited when participants imagine themselves in the future. The second subsystem, referred to as the dorsomedial prefrontal cortex (dmPFC) subsystem, includes the dmPFC and lateral temporal cortex (among other regions), and it is most strongly activated when participants think about their 
present mental states. These and other findings have led to the hypothesis that the $\mathrm{DN}$ is associated with a variety of self-referential functions, including introspection, remembering, and planning (Broyd et al, 2009; Buckner et al, 2008; Raichle et al, 2001). In this conceptualization, the DN allows 'event scenarios to be construed, replayed, and explored to enrich the remnants of past events in order to derive expectations about the future' (p. 31; Buckner et al, 2008).

How are these data relevant to the association between increased resting rACC activity and better treatment response? Given the link between introspection and increased activation of the $\mathrm{DN}$, including the $\mathrm{rACC}$, one might expect that increased resting rACC activity would be linked with rumination, a repetitive and passive focus on depressive symptoms, and their causes and consequences (Nolen-Hoeksema, 1991). This is important because increased rumination has been found to predict depression onset, higher levels of depressive symptoms, and poor outcome (eg, Kuehner and Weber, 1999; see NolenHoeksema et al, 2008 for review). However, emerging evidence suggests that rumination also has adaptive components. For example, analysis of a widely used rumination scale - the Ruminative Responses Scale (RRS) - identified two different components: reflective pondering and brooding (Treynor et al, 2003). Reflective pondering included items such as, 'analyze recent events to try to understand why you are depressed,' and was conceptualized as capturing 'a purposeful turning inward to engage in cognitive problem solving to alleviate one's depressive symptoms' (p. 256). In contrast, brooding included items like, 'Think 'What am I doing to deserve this?" and was conceived as 'a passive comparison of one's current situation with some unachieved standard' (p. 256). In line with this multidimensional conceptualization of rumination, elevated scores on the reflective and brooding subscales predicted lower and higher levels of depressive symptoms 1 year later, respectively (Treynor et al, 2003).

Along similar lines, additional research indicates that the self-focused nature of rumination is not necessarily associated with negative effects. Rather, it is the mode of processing adopted during self-focused attention that appears to distinguish the maladaptive rumination often observed in depression (eg, Crane et al, 2007; Sanders and Lam, 2010; Watkins and Teasdale, 2004). Specifically, a mindful, nonevaluative focus on thoughts, feelings, and physical sensations occurring in the moment can have beneficial cognitive effects (Crane et al, 2007; Watkins and Teasdale, 2004) and prevent relapse (eg, Ma and Teasdale, 2004) in depression. Conversely, an 'analytic self-focus,' in which participants think about the causes, meaning, and consequences of depressed mood (analogous to brooding) has been found to exacerbate depression (Nolen-Hoeksema et al, 2008; Watkins and Teasdale, 2004).

Based on these findings, I propose that increased resting rACC activity may be linked to adaptive aspects of rumination characterized by cognitive problem solving (Treynor et al, 2003), the development of alternative interpretations of negative thoughts and feelings (Watkins and Teasdale, 2004), adaptive preparation and anticipatory planning (Watkins, 2008), and/or a mindful, nonevaluative self-focus. As discussed in the next section, these kinds of adaptive interactions between affective and cognitive processes might also involve interplay between the DN and the task-positive network, which includes the DLPFC and dACC, as well as modulation of limbic regions, particularly the amygdala (Figure 3a). Critically, depression has been associated with dysregulated interactions among these networks (Figure $3 \mathrm{~b}$ ), as well as functional and structural abnormalities in the rACC, dACC, and DLPFC. I suggest that dysregulated interplay among these networks is linked to maladaptive forms of rumination and other important psychological facets of depression, including prolonged negative affect, increased elaboration of negative information, impaired ability to disengage from negative cues, and reduced cognitive control when challenged with negative information (see Gotlib and Joormann, 2010 for an excellent review of the clinical and experimental literature on biased emotional processing in depression).

\section{Anticorrelated Functional Networks}

Because activity in the DN typically decreases during performance of laboratory tasks, the $\mathrm{DN}$ is often referred to as a task-negative network (Broyd et al, 2009; Fox et al, 2005). The DN contrasts with a task-positive network (TPN), which includes the DLPFC, dACC, the intraparietal sulcus, and middle temporal area, among other regions (Figure 2). As its name implies, the TPN becomes activated during tasks requiring cognitive and attentional resources (Corbetta and Shulman, 2002; Sounuga-Barke and Castellanos, 2007). Critically, these two networks are temporally anticorrelated during both resting and activated states (Drevets and Raichle, 1998; Fox et al, 2005; Kelly et al, 2008; Mannell et al, 2010; Margulies et al, 2007; but see Van Dijk et al, 2010 for important methodological caveats regarding the interpretation of anticorrelations in functional neuroimaging data). For example, studies of resting state functional connectivity report negative correlations between the rACC and AACC, along with positive correlations between the DLPFC and AACC, the two regions implicated in cognitive control (Fox et al, 2005; Margulies et al, 2007).

Supplementing these resting data, increases in cognitive load and task difficulty have been associated with increased activation of the TPN and greater deactivation of the DN (eg, McKiernan et al, 2003; Pallesen et al, 2009; Tomasi et al, 2006), including the rACC (Pallesen et al, 2009; Persson et al, 2007; Polli et al, 2005). In controls, reduced suppression of the DN during demanding tasks has been linked to attentional lapses (Weissman et al, 2006) and errors in performance ( $\mathrm{Li}$ et al, 2007a). Collectively, these findings suggest that in cognitively demanding situations, introspective processing is replaced by a state of alertness and attention to environmental cues (Broyd et al, 2009; Buckner et al, 2008). Thus, adaptive regulation of cognition 

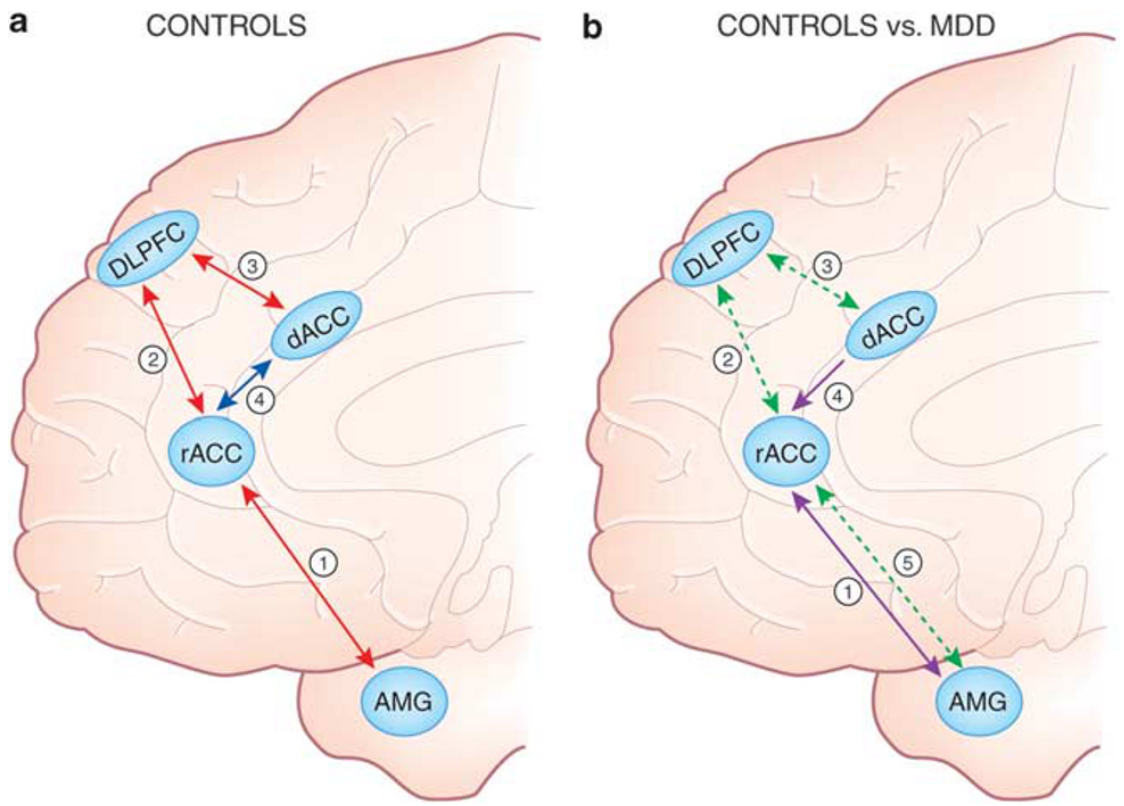

Figure 3. (a) Schematic representation of frontocingulate and frontolimbic interactions associated with adaptive forms of reflective, self-focused processing, as well as adaptive regulation of cognition and emotions. In controls, increased resting rACC activity as well as functional coupling (positive correlations) between the rACC and amygdala (see arrow 1) are observed during resting states (Margulies et al, 2007) and self-referential processing (Schmitz and Johnson, 2006). When confronted with cognitive or affective challenges, healthy controls show increased coupling (positive correlations) between the (1) rACC and DLPFC (arrow 2; Holmes and Pizzagalli, 2008b; Etkin et al, 2006) and (2) DLPFC and dACC (arrow 3; Aizenstein et al, 2009; Fox et al, 2005; Margulies et al, 2007; Schmitz and Johnson, 2006). The interplay among these regions is hypothesized to reduce task-induced rACC activation (arrow 4; Drevets and Raichle, 1998; Fox et al, 2005; Margulies et al, 2007) and downregulate amygdala activation, fostering adaptive regulation of cognition and emotions. (b) Relative to controls, MDD subjects show stronger functional coupling (positive correlations) between the rACC and the amygdala during negative self-referential processing (arrow 1; Yoshimura et al, 2010) as well as reduced structural connectivity between these two regions (arrow 5; Cullen et al, 2010). In addition, relative to controls, MDD subjects show reduced functional connectivity between the (1) rACC and DLPFC (arrow 2; Holmes and Pizzagalli, 2008b; Siegle et al, 2007) and (2) DLPFC and dACC (arrow 3; Aizenstein et al, 2009; Schlösser et al, 2008), but abnormally elevated functional connectivity between the dACC and rACC (arrow 4; Schlösser et al, 2008) during cognitive and/or affective challenges. The dysregulated interplay among these regions is hypothesized to lead to failures to deactivate the rACC and amygdala during affective and cognitive challenges, fostering the emergence of maladaptive forms of rumination, and ultimately treatment nonresponse. Numbers do not reflect chronological unfolding of interactions among brain regions.

appears to include suppression of resting rACC activity during demanding tasks. [Note: It should be noted that four studies have reported a link between increased task-related rACC activity and favorable antidepressant response. With one exception (Langenecker et al, 2007), these studies involved passive observation of emotionally valenced stimuli (Chen et al, 2007; Davidson et al, 2003; Salvadore et al, 2009), and thus minimal cognitive challenge. The observation of rACC activity in these studies is consistent with data in healthy controls showing that simple tasks requiring minimal cognitive demands are associated with relatively preserved DN activity (Grecius et al, 2003; Wilson et al, 2008)].

In MDD, functional and structural abnormalities within frontocingulate pathways (see the section 'Frontocingulate dysfunction in major depression: the empirical evidence and clinical correlates') might disrupt coupling between the DN and TPN, which could contribute to maladaptive forms of self-focused processing and rumination. Specifically, I speculate that the inability to reduce activity in the DN, and/ or dominance of the DN over the TPN, coupled with impairments in modulating amygdalar activity, is linked to excessive negative self-introspection and maladaptive (eg, brooding) rumination (Sheline et al, 2009; Yoshimura et al, 2009). This disrupted coupling might also affect the recruitment of cognitive control in situations requiring inhibition of negative information or adaptive adjustments following errors, which is relevant to the widely reported finding of impaired post-error performance in MDD (see the section 'Frontocingulate dysfunction in major depression: the empirical evidence and clinical correlates').

Converging evidence for this hypothesis comes from the fact that various disease states associated with blunted resting rACC activity, including schizophrenia (Fletcher et al, 1998), dementia (Lustig et al, 2003), and autism (Kennedy et al, 2006), are characterized by reduced taskinduced rACC deactivation, although the possibility that this reflects a floor effect needs to be evaluated. Initial evidence suggests that this link extends to depression (Grimm et al, 2009). Complementary evidence includes the fact that conditions characterized by diminished cognitive control, including sleep deprivation (eg, Chee and Choo, 2004) and aging (Persson et al, 2007), are associated with reduced DN deactivation. Thus, I propose that decreased resting rACC activity-hypothesized to reflect reduced ability to engage in adaptive self-focused processing - and 
reduced task-induced rACC deactivation-hypothesized to reflect an inability to deactivate the DN, recruit the TPN, and/or provide top-down regulation of limbic regions during cognitively challenging or affectively evocative situations - represent important components of frontocingulate dysfunction linked to maladaptive emotional and self-focused processing, cognitive control impairments, and poor treatment outcome (Figure 3). The evidence pointing to abnormalities within frontocingulate pathways in depression is reviewed next.

\section{FRONTOCINGULATE DYSFUNCTION IN MAJOR DEPRESSION: THE EMPIRICAL EVIDENCE AND CLINICAL CORRELATES}

\section{Neuropsychological Studies}

A large literature points to wide-ranging neuropsychological deficits in MDD (for reviews, see Austin et al, 2001; Castaneda et al, 2008; Hammar and Ardal, 2009). Impaired executive functions - which rely on frontal lobe structures and are pivotal for directing attention, inhibiting behavior, generating strategies, planning, monitoring ongoing performance, and coding representations in working memory (Baddeley, 1998; Leh et al, 2010; Smith and Jonides, 1999) - have emerged as one of the core cognitive deficits in depression (eg, Austin et al, 2001). Executive dysfunction: (1) is evident in the acute depressed phase (eg, Channon and Green, 1999; Pizzagalli et al, 2006; Porter et al, 2003); (2) is exacerbated in more severely depressed subjects (eg, Paelecke-Habermann et al, 2005); (3) persists after remission (eg, Hammar et al, 2009; Paelecke-Habermann et al, 2005; Paradiso et al, 1997; Smith et al, 2006; Trichard et al, 1995; Weiland-Fiedler et al, 2004; but see Biringer et al, 2007); (4) predicts poor response to pharmacological treatment (eg, Alexopoulos et al, 2005; Dunkin et al, 2000; Gorlyn et al, 2008; Sneed et al, 2007); and (5) worsens with increasing numbers of prior depressive episodes (Kessing, 1998; Sweeney et al, 2000). Altogether, these data indicate that executive dysfunction is an important feature of depression, and that recovery from depression precedes normalization of executive dysfunction.

Several points emerging from this literature are particularly important for the current review, and will be emphasized. First, executive deficits have emerged more consistently in tasks requiring effortful (rather than automatic) processing as opposed to speeded motor output (eg, Gorlyn et al, 2008; Hammar et al, 2009; Levens et al, 2009; Weiland-Fiedler et al, 2004; but see Den Hartog et al, 2003). These selective deficits point to impairments in cognitive control, which encompasses attentional allocation, inhibition of task-irrelevant information, monitoring of performance, and adaptive behavioral adjustments after committing errors or receiving performance-related feedback (MacDonald et al, 2000; Ridderinkhof et al, 2004) Second, numerous studies have found that, relative to controls, currently as well as formerly depressed subjects perform less accurately immediately after committing a mistake, raising the possibility that oversensitivity to errors might play a key role in cognitive control deficits in depression (Beats et al, 1996; Compton et al, 2008a; Elliott et al, 1996; Elliott et al, 1997b; Holmes and Pizzagalli, 2007, 2008b; Jones et al, 2010; Murphy et al, 2003; Pizzagalli et al, 2006; Steffens et al, 2001; but see Purcell et al, 1997 and Shah et al, 1999). These findings have been extended by observations that negative feedback disrupts performance and decision making in the subsequent trial in both currently depressed (Murphy et al, 2003) and unmedicated remitted (Taylor Tavares et al, 2007) samples.

Collectively, these findings suggest that 'catastrophic responses to failures' (Beats et al, 1996), that is, deterioration of executive function and performance after error commission or negative performance feedback, might represent a trait-like marker of depression. This is consistent with the fact that psychiatrically healthy individuals carrying genetic variants linked to increased risk of depression also demonstrate abnormal behavioral, electrophysiological, and hemodynamic responses to errors (eg, Beste et al, 2010; Fallgatter et al, 2004; Holmes et al, 2010).

Psychological concomitants of executive dysfunction in depression. Although the neuropsychological literature reviewed above has provided important clues about the nature, extent, and persistence of executive dysfunction in MDD, little is known about associated psychological processes. One possibility is that the tendency to engage in maladaptive rumination might interfere with or deplete cognitive resources needed to perform a primary task, resulting in poor behavioral performance (Beck, 2008; Holmes and Pizzagalli, 2008b; Jones et al, 2010). Although a direct test of this hypothesis is challenging, promising evidence has emerged from both behavioral and functional neuroimaging literature.

With respect to behavioral evidence, several studies deserve mention. Davis and Nolen-Hoeksema (2000) showed that people with high ruminative tendencies committed more perseverative errors in the Wisconsin Card Sorting Task. In a more recent study, individuals with MDD were found to have difficulties ignoring negative (but not positive or neutral) distractors embedded in narratives, as indexed by increased reading time (Lau et al, 2007). These impairments emerged despite normative performance in a Stop Signal task, suggesting that deficits in cognitive control/inhibition may be dissociated from motor/ behavioral response inhibition (Dillon and Pizzagalli, 2007). Furthermore, MDD subjects with the greatest difficulty in inhibiting task-irrelevant negative cues reported the greatest degree of negative automatic thinking and trait ruminative tendencies. These findings indicate that deficits in cognitive inhibition may be a key mechanism underlying the development and maintenance of depressive cognition (eg, 
Joormann and Gotlib, 2010; see Gotlib and Joormann, 2010 for review).

Additional evidence of a link between impaired performance in executive tasks and resource allocation to taskindependent, self-focused processing emerged from a study measuring pupil motility in depressed and control subjects during a task requiring continuous controlled processing - the Paced Auditory Serial Addition Task (PASAT) (Jones et al, 2010). The authors hypothesized that pupil motility occurring at the frequency of the stimulus presentation would reflect task-relevant processing. Conversely, pupil motility at lower frequencies was assumed to index taskirrelevant processing, including longer lasting intrinsic processing (eg, rumination). Relative to controls, MDD subjects committed more consecutive errors and displayed less task-related frequencies and more off-task frequencies during the PASAT. Moreover, off-task power (a putative index of intrinsic, non-task-related processing) was positively correlated with rumination and partially mediated the link between poor post-error adjustments and depression status. These findings were interpreted as suggesting that engagement in self-focused processing (eg, maladaptive rumination) might deplete or interfere with controlled processing.

Although these findings are interesting, the direction of causality between executive dysfunction and rumination is unclear: does a primary dysfunction in executive function (particularly, cognitive control) allow the emergence of maladaptive ruminative thought, or does rumination cause executive dysfunction because it constitutes a cognitive load that leads to diminished cognitive flexibility? [In this context, it is important to emphasize that, unlike maladaptive forms of rumination (eg, brooding, analytic self-focus attention), adaptive forms of rumination (eg, a mindful, nonevaluative focus) have been hypothesized to be cognitively less effortful (Teasdale, 1999). Accordingly, adaptive forms of rumination linked to increased resting rACC activity might be less cognitively taxing.] In an initial step toward exploring putative links between executive dysfunction and rumination, Watkins and Brown (2002) engaged depressed patients and matched controls in an executive task (random number generation) after inducing rumination or distraction. In contrast to controls, depressed participants who engaged in maladaptive rumination displayed stereotyped counting behavior (an index of reduced inhibitory executive control), but there were no group differences after the distraction induction. These results suggest that depression may confer vulnerability to the disruptive effects of rumination on cognitive control. Because MDD subjects presumably had varying degrees of executive dysfunction, these findings, although promising, do not provide definitive answers about the causal links between executive dysfunction and rumination.

\section{Structural Neuroimaging Studies}

Volumetric studies. Findings in the previous sections indicate that depression is characterized by impaired executive function, especially deficient cognitive control. A large body of work has pointed to the frontal cortex as the major brain region implicated in executive function (eg, Luria, 1971; Shallice, 1982; see Leh et al, 2010 for a recent review). Cognitive control can be further decomposed into evaluative and executive components (Botvinick et al, 2001; van Veen and Carter, 2006). The evaluative component (assumed to be subserved by the dACC) has been hypothesized to monitor whether events or outcomes are worse than expected. The executive component (assumed to rely on the DLPFC) has been hypothesized to use such evaluations to implement adaptive behavioral adjustments. In light of the behavioral data reviewed above, it is plausible to expect structural abnormalities within frontocingulate pathways in MDD. In the following sections, a summary of studies investigating morphometric and volumetric features of the ACC and DLPFC in depression is provided (see Koolschijn et al, 2009; Lorenzetti et al, 2009 for reviews summarizing other brain regions).

rACC volume in depression. Relative to controls, individuals with MDD - including medication-naive individuals with a first major depressive episode (MDE) (Tang et al, 2007) - are often characterized by reduced rACC volume or gray matter concentration (Abe et al, 2010; Boes et al, 2008; Frodl et al, 2008b; Leung et al, 2009; Mak et al, 2009; Tang et al, 2007; Treadway et al, 2009). In a 3-year prospective study, MDD subjects showed a significantly larger decline in rACC and DLPFC volume than controls, and reductions were largest in individuals failing to remit during the 3 years (Frodl et al, 2008b).

Particularly relevant to the current review are findings highlighting clinical and functional correlates of these volumetric abnormalities. In MDD treatment studies, a smaller rACC volume predicts poor treatment response and more frequent hospitalization (Chen et al, 2007; Costafreda et al, 2009a; Frodl et al, 2008a; Gunning et al, 2009). Moreover, among depressed individuals, reduced rACC volume or gray matter concentration has been linked to greater depression severity (Boes et al, 2008; Leung et al, 2009), attentional biases toward negative words (Leung et al, 2009), and diminished ability to downregulate negative (but not positive) emotions in a laboratory task (Mak et al, 2009). These findings are complemented and extended by the observation of reduced magnetization transfer ratio-assumed to reflect demyelination - in the rACC and AACC of individuals with treatment-resistant depression (Zhang et al, 2009). Together, these data indicate that reduced rACC volume: can be seen at the first MDE; is exacerbated by illness severity; characterizes nonremission; predicts poor outcome; and is associated with selective attention toward negative cues in the environment and difficulty in downregulating negative emotion.

dACC volume in depression. Relatively few studies have investigated dACC volume in depression, and inconsistencies exist. Reduced dACC volume has been reported in some 
(eg, Ballmaier et al, 2004; Caetano et al, 2006; Vasic et al, 2008) but not all (Frodl et al, 2008a; Yuan et al, 2008) studies. dACC volume reduction has been observed in unmedicated subjects with a past history of MDD (Caetano et $a l, 2006)$, raising the possibility that reduced dACC volume might not normalize after remission. These findings contrast, however, with null findings emerging from medicated samples, in which normative dACC volume was reported in both currently depressed (Frodl et al, 2008a) and remitted depressed (Bremner et al, 2002) individuals. Finally, reduced dACC gray matter volume was associated with worse executive function (Vasic et al, 2008) and lack of initiative and interest, flat affect, and emotional indifference (Lavretsky et al, 2007).

DLPFC volume in depression. Reduced volume or gray matter concentration in the DLPFC (generally involving the superior and middle frontal gyrus in both hemispheres; BA 9/46) has emerged in several studies (Abe et al, 2010; Ballmaier et al, 2004; Bell-McGinty et al, 2002; Coffey et al, 1993; Frodl et al, 2008b, 2010; Kumar et al, 1998; Leung et al, 2009; Li et al, 2010; Mak et al, 2009; Vasic et al, 2008; Yuan et al, 2008). Reduced left DLPFC volume predicted longer illness duration (Frodl et al, 2010), correlated with increased depression severity (Kumar et al, 1998; Li et al, 2010), and was linked to nonremission after a 6-week antidepressant treatment ( $\mathrm{Li}$ et al, 2010). Moreover, decreased gray matter concentration in the right DLPFC correlated with increased depression severity and worse executive functioning (Vasic et al, 2008), as well as attentional biases toward negative cues (Leung et al, 2009).

\section{Diffusion Tensor Imaging (DTI) Studies}

Data reviewed in the last section highlight morphometric abnormalities within frontocingulate pathways in MDD. Although important, these data do not speak to the issue of possibly abnormal structural connectivity in these pathways in MDD (eg, Mayberg et al, 2002). In the following sections, I review emerging data, mostly obtained with DTI, that point to structural abnormalities within frontocingulate and frontolimbic pathways.

DTI is a relatively new technique that can be used to investigate white matter tracts through the study of the diffusion of water in tissues, which can be indexed by fractional anisotropy (Taylor et al, 2004). Anisotropy indexes the extent to which diffusion of water molecules is directionally dependent, and is high in healthy white matter (because water mostly moves parallel - rather than perpendicular - to fibers). Accordingly, reduced fractional anisotropy can be interpreted as a marker of white matter abnormalities or fiber density reduction. In depression, reduced fractional anisotropy within PFC and ACC white matter has been described in adolescent (Cullen et al, 2010), young adult (Li et al, 2007b), and elderly (eg, Bae et al, 2006; Nobuhara et al, 2006; Shimony et al, 2009) samples. This abnormality, which has also emerged in first-episode, treatment-naive young adults with MDD (Ma et al, 2007), is important because it affects fibers of the DLPFC circuit implicated in executive function and effortful regulation of behavior (Tekin and Cummings, 2002). Medicated depressed adolescents were also characterized by reduced fractional anisotropy in tracts connecting the supragenual ACC to the right amygdala (Cullen et al, 2010), suggesting the possibility of diminished regulatory input to the amygdala. In a recent study, fractional anisotropy in the left frontal and AACC white matter was inversely correlated with total days depressed (Abe et al, 2010), raising the possibility that cumulative disease burden is associated with increasing disconnection between frontoncingulate pathways. Moreover, reduced fractional anisotropy within frontal white matter thought to project to limbic regions was found to be related to increased depression severity (Nobuhara et al, 2006).

Of primary relevance to the current review, reduced anisotropy in white matter lateral to the cingulate gyrus (ie, tracts containing fibers of the ACC and DLPFC pathways) predicted poor treatment response in a small sample with geriatric depression (Alexopoulos et al, 2002). In an extension of this work, nonremission after a 12-week escitalopram treatment was associated with reduced fractional anisotropy in multiple frontal areas, including the rACC, dACC, and DLPFC (Alexopoulos et al, 2008; but see Taylor et al, 2008 for contrasting findings). Finally, relatively preserved integrity of these white matter tracts positively correlated with better Stroop performance (better response inhibition) (Alexopoulos et al, 2002; Murphy et al, 2007) and cognitive processing speed (Shimony et al, 2009).

\section{Functional Neuroimaging Studies}

Frontocingulate activation during executive tasks. In line with the view that depression is characterized by abnormalities within the TPN, dysfunctional frontocingulate activation during a variety of executive tasks is one of the most consistent findings in the neuroimaging literature of depression, although interesting dissociations have emerged depending on behavioral performance. In general, reports of blunted activation in AACC and DLPFC regions have emerged from studies reporting reduced task-related behavioral performance in MDD subjects (eg, Audenaert et al, 2002; Elliott et al, 1997a; Elliott et al, 1997b; George et al, 1997; Holmes and Pizzagalli, 2008a; Okada et al, 2003; but see Halari et al, 2009; Harvey et al, 2005; Hugdahl et al, 2004). Recent data indicate that reduced activation in DLPFC and dACC: (1) can be observed in unmedicated adolescents with MDD, indicating that such dysfunctions appear early in the disorder (Halari et al, 2009); and (2) does not normalize in medicated individuals in recovery with multiple MDEs (Aizenstein et al, 2009). Furthermore, consistent with the possibility that blunted dACC activation might be associated with increased depression vulnerability, decreased dACC blood flow has been observed in healthy controls with personal or familial history of depression after tryptophan depletion (Talbot and Cooper, 2006). 
Findings of blunted frontocingulate activation contrast with numerous reports of over-recruitment of these brain regions during executive tasks in depression. Interestingly, potentiated rACC (Rose et al, 2006; Wagner et al, 2006; Walter et al, 2007), dACC (Harvey et al, 2005; Rose et al, 2006; Wagner et al, 2006), and left DLPFC (Fitzgerald et al, 2008; Harvey et al, 2005; Holmes et al, 2005; Matsuo et al, 2007; Wagner et al, 2006; Walter et al, 2007) activation has emerged from studies in which MDD subjects performed at the same level as healthy comparison subjects. For example, relative to controls, medicated MDD subjects showed significantly higher left DLPFC activation during the highest cognitive load condition of a delayed match-to-sample working memory task in the context of no behavioral differences (Walter et al, 2007; see also Harvey et al, 2005). Critically, increased DLPFC and ACC activation in executive control tasks in the context of normative behavioral performance has emerged in both medicated (eg, Harvey et al, 2005; Rose et al, 2006; Walter et al, 2007) and unmedicated (eg, Matsuo et al, 2007) individuals with MDD, indicating that over-recruitment of frontocingulate pathways is not due to medication status. Moreover, recent findings suggest that rACC hyperactivation during executive tasks persists after remission (Schoning et al, 2009).

Mounting evidence indicates that higher rACC activation in depressed individuals relative to healthy controls during executive tasks might stem from a failure to deactivate the rACC as cognitive load increases (Rose et al, 2006; Vasic et al, 2009; Wagner et al, 2006). For example, during incongruent Stroop trials, MDD subjects showed hyper- activity in the rACC but normative dACC activation and performance (Wagner et al, 2006). Within-group analyses showed a stronger deactivation of the rACC during the incongruent relative to congruent condition for controls, consistent with prior findings that task-related rACC deactivation is required for optimal cognitive control (Bush et al, 2000; Drevets and Raichle, 1998). Notably, in the depressed group this pattern was reversed, as they showed elevated rACC activation during incongruent relative to congruent trials. Finally, among MDD subjects, task-related rACC hyperactivity correlated with increased Stroop interference effects. Collectively, these findings are consistent with the notion that a failure to deactivate the $\mathrm{DN}$ during cognitively demanding tasks is an important concomitant of executive dysfunction in depression.

However, a failure to suppress one of the main DN hubs (rACC) may only be one aspect of abnormal emotioncognition interplay in MDD. In line with this proposition, two recent studies have provided important insights into unfolding of functional connectivity between ACC regions implicated in automatically responding to salient cues and DLPFC regions implicated in cognitive control. Using highdensity ERPs and source localization techniques, Holmes and Pizzagalli (2008b) recently reported that unmedicated MDD subjects were characterized by (1) potentiated rACC responses $80 \mathrm{~ms}$ after committing an error in a Stroop task (Figure 4a), and (2) decreased functional connectivity between rACC activation $80 \mathrm{~ms}$ post-error and left DLPFC $472 \mathrm{~ms}$ post-error (Figure $4 \mathrm{~b}$ ). Thus, unlike controls, MDD subjects showing the strongest rACC reactivity to errors

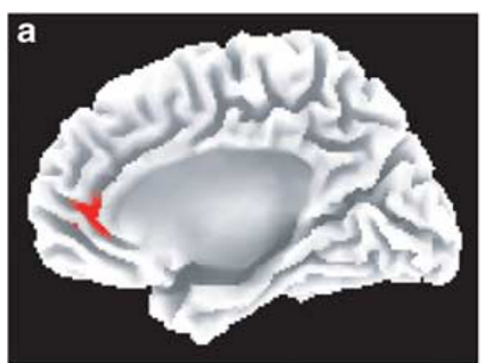

80 ms post-error

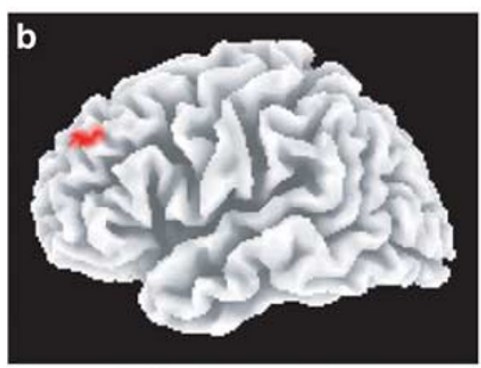

472 ms post-error

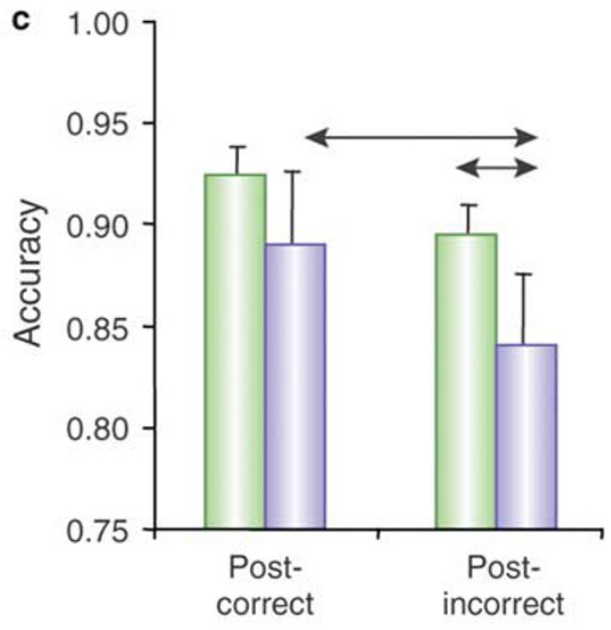

MDD with high left DLPFC MDD with low left DLPFC

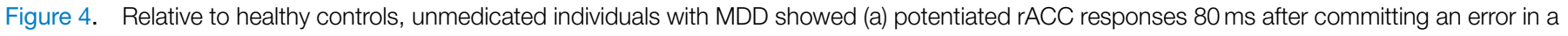

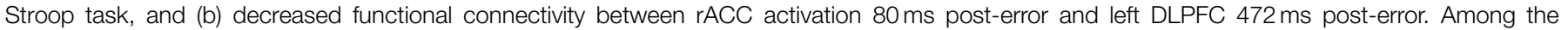

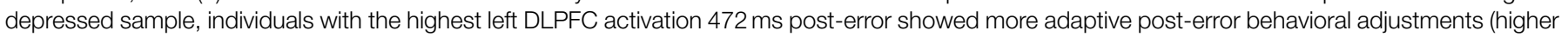

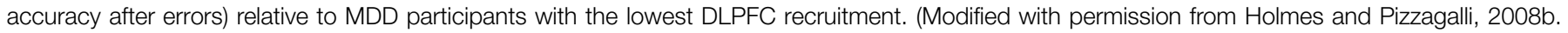
Copyright (C) 2008 American Medical Association. All rights reserved). 
failed to recruit left DLPFC regions implicated in cognitive control (Kerns et al, 2004). Interestingly, in the depressed sample, individuals with the highest left DLPFC activation $472 \mathrm{~ms}$ post-error showed more adaptive post-error behavioral adjustments (higher accuracy and slower response after errors) relative to MDD participants with the lowest DLPFC recruitment (Figure 4c). These findings are consistent with prior evidence in healthy controls that ACC activation during a high-conflict trial predicted greater DLPFC activation, which in turn was linked to more adaptive behavioral adjustments (Kerns et al, 2004). Interestingly, these behavioral and neural differences emerged in spite of virtually identical depression severity scores between the two MDD subgroups (mean Beck Depression Inventory scores: $22.11 \pm 9.45$ vs $22.22 \pm 9.46$ ), suggesting the existence of MDD subgroups that may not be readily identified by differences in self-reported symptoms (Holmes and Pizzagalli, 2008b).

These findings were conceptually replicated and extended by Aizenstein et al (2009), who engaged an elderly depressed sample in a modified version of the Stroop task. When presented with high-load trials, MDD subjects showed reduced left DLPFC activation relative to controls. Moreover, relative to controls, MDD subjects showed reduced functional connectivity between dACC in the current trial and the DLPFC in the subsequent trial (Aizenstein et al, 2009). Of primary relevance, whereas DLPFC activation normalized (ie, increased) after a 12-week treatment with paroxetine, reduced frontocingulate functional connectivity persisted after symptom improvements, highlighting a possible marker linked to increased vulnerability for future depression.

Summary. Altogether, these data indicate that, relative to controls, depressed individuals must recruit frontocingulate regions to a greater extent in order to achieve similar levels of behavioral performance, highlighting inefficiency within frontocingulate pathways during tasks requiring cognitive control. In more challenging cognitive tasks, blunted DLPFC and dACC activation has generally accompanied reduced behavioral performance in depressed individuals. In addition, in contrast to controls, depressed individuals fail to deactivate the rACC during cognitively demanding tasks and are characterized by reduced recruitment of DLPFC regions in situations requiring increased cognitive control (high-conflict trials and post-error trials). As discussed in the section 'The rostral ACC as a key hub within the DN,' difficulties in deactivating this hub of the $\mathrm{DN}$, bringing online the TPN during cognitive tasks, and providing top-down regulation of limbic (amygdala) regions might foster the emergence of maladaptive emotional and self-focused processing, leading to treatment nonresponse. Two sets of findings are consistent with this assumption. First, in a recent MEG study, Salvadore et al (2010) reported that patients with the smallest rACC recruitment as a function of increasing working memory load in an N-back task showed the greatest reduction in depressive symptoms after acute ketamine administration. Second, in studies with healthy subjects, reduced taskinduced rACC deactivation has been associated with increased interference during an affective Eriksen flanker task (Ochsner et al, 2009) and predicted errors in both an executive task (Li et al, 2007a) and an antisaccade task (Polli et al 2005). In spite of this promising evidence, no study has investigated putative links among resting ACC activity, task-induced rACC deactivation, and treatment outcome in depression, or has probed psychological mechanisms underlying these associations. Along similar lines, it is currently unknown whether the rACC region whose resting activity predicts better antidepressant response overlaps anatomically with the one showing reduced task-related deactivation in MDD and/or whether each region might possess stronger functional/structural connectivity with the TPN or amygdala.

\section{Frontocingulate Activation During Affective Tasks}

A failure to deactivate $\mathrm{rACC}$ regions and abnormal patterns of frontocingulate activation have also emerged in studies testing depressed individuals with a variety of affective tasks, highlighting the robustness of these findings. Specifically, hyperactivation or reduced deactivation of rACC regions in MDD subjects has been observed during (1) affective evaluation and cognitive reappraisal of negative pictures (Grimm et al, 2009; Sheline et al, 2009; Walter et al, 2009); (2) self-referential processing of negative words (Siegle et al, 2007; Yoshimura et al, 2010); (3) inhibition of negative (but not positive) words (Eugene et al, 2010); and in response to (4) sad words in an emotional Stroop task (Mitterschiffthaler et al, 2008); (5) sad nogo words in an affective go/nogo task (Elliott et al, 2002); and (5) errors in an emotional conflict task (Fales et al, 2008) and Stroop task (Holmes and Pizzagalli, 2008b).

Several features of the findings deserve emphasis. First, reduced task-related rACC deactivation during affective evaluation of emotional pictures correlated with increasing illness severity, in particular depressed mood, depressive cognitions, and suicidal ideation (Grimm et al, 2009; see also Yoshimura et al, 2010). Along similar lines, a failure to deactivate rACC regions in response to negative stimuli has been associated with increased interference to sad words in an emotional Stroop task (Mitterschiffthaler et al, 2008). In a study investigating neural correlates of grief regulation, Freed et al (2009) reported that rACC activation in response to words associated with the deceased correlated with intrusive thoughts of the deceased; moreover, functional connectivity between rACC and left amygdala correlated with ratings of sadness and yearning/missing. Collectively, these findings are consistent with the assumption that failure to suppress the DN is associated with biased emotional processing and maladaptive cognition in depression, which would negatively impact treatment response. Providing initial evidence for this hypothesis, potentiated rACC responses to sad faces 2 weeks after onset of 
antidepressant treatment predicted poor response at least 8 weeks later (Keedwell et al, 2010).

Second, relative to controls, depressed individuals are not only characterized by a failure to deactivate rACC regions in affective tasks, but also by reduced ability to recruit the DLPFC (Fales et al, 2008; Holmes and Pizzagalli, 2008b; Mitterschiffthaler et al, 2008; Wang et al, 2008a, 2008b; Siegle et al, 2007) and dACC (Fales et al, 2008; Wang et al, 2008a, 2008b) when required to ignore task-irrelevant negative cues or adjust behavior after committing errors. Deficient recruitment of task-positive regions has been further accompanied by potentiated activation in the amygdala when (1) viewing and reappraising negative pictures (Sheline et al, 2009), (2) processing negative words self-referentially (Siegle et al., 2007), (3) attempting to ignore negatively (but not positively) valenced distractors (Fales et al, 2008), and (4) in response to negative feedback (Taylor Tavares et al, 2008) and maternal criticisms (Hooley et al, 2009). In addition, relative to controls, MDD subjects have been found to show higher functional connectivity between the rACC and amygdala during negative selfreferential processing (Yoshimura et al, 2010). Together, these data point to a dominance of the $\mathrm{DN}$ and limbic regions implicated in automatic responses to emotional cues (eg, amygdala) over TPN regions in MDD, highlighting deficits in implementing top-down processes over emotional responsiveness (see also Mayberg et al, 2002).

An important question is whether the frontocingulate and limbic dysfunctions described above normalize after successful treatment. Initial data suggest that some, but not all, components normalize after symptom remission. For example, Fales et al (2009) recently reported that after 8 weeks of antidepressant treatment with SSRIs, MDD subjects showed similar responses in the DLPFC and amygdala as controls when instructed to ignore sad faces. In contrast, relative hyperactivity in the rACC and hypoactivation in the dACC persisted after treatment response. Persistent dACC hypoactivation and failure to deactivate the DN was also observed in a remitted sample tested with an emotional oddball task (Wang et al, 2008a).

Whereas these studies provide clues about normalization of activation level within single regions, two studies probed treatment-induced changes in resting state functional connectivity. Common among these studies was the finding that antidepressant treatment and reductions in depressive symptoms were associated with increased functional connectivity between frontocingulate regions (rACC and right DLPFC) and the amygdala (Anand et al, 2005; Chen et al, 2007). In light of neuroimaging data highlighting the role of frontocingulate-mediated downregulation of amygdalar reactivity in emotion regulation (Ochsner and Gross, 2005), increased corticolimbic coupling might reflect better emotional regulation abilities. Providing some support for this speculation, increased connectivity between the pregenual/dACC and limbic regions at rest correlated with decreased fMRI amygdalar activation to negative stimuli (Anand et al, 2007).
Summary. During affective challenges, acutely depressed as well as euthymic individuals with a history of depression are characterized by hyperactivation and/or reduced deactivation in rACC regions implicated in evaluating the subjective, emotional, and motivational significance of events (Bush et al, 2000; Simoes-Franklin et al, 2010; Taylor et al, 2006). This dysfunction is accompanied by deficits in recruiting regions critical for cognitive control and emotional regulation, such as the DLPFC and dACC (Miller and Cohen, 2001; Ochsner and Gross, 2005), and potentiated amygdalar responses in tasks requiring passively observing, actively ignoring, or cognitively reappraising negative information. Collectively, these data indicate that dysfunction within frontocingulate pathways, and in particular reduced taskinduced rACC deactivation, is associated with diminished cognitive control over emotional responses and reduced ability to divert attention from negative emotional states (Fales et al, 2008; Sheline et al, 2008). Although very few studies have investigated functional correlates of frontocingulate dysfunction in depression (eg, Eugene et al, 2010; Mitterschiffthaler et al, 2008), these neuroimaging data are consistent with behavioral evidence linking depression with difficulties in disengaging from and inhibiting negative cues (Goeleven et al, 2006; Koster et al, 2005; Lau et al, 2007), potentiated interference from negative distractors (Gotlib et al, 2004), amplification of the significance of failure (Wenzlaff and Grozier, 1988), and 'catastrophic' reactions to errors.

\section{CONCLUSIONS AND FUTURE DIRECTIONS}

MDD remains a leading cause of disability worldwide and is associated with profound personal suffering and staggering costs to society (Greenberg et al, 2003; Holma et al, 2010; Lopez et al, 2006). Despite an array of antidepressant options and psychotherapies, there is currently no empirically validated approach to selection of treatment that is based on an individual's likelihood of response to a given therapy. As a result, treatment in clinical practice follows a trial-and-error approach. The goals of the current review were: (1) to perform a meta-analysis to evaluate the promise of resting rACC activity as a biomarker of treatment response in depression; (2) to advance hypotheses concerning psychological and neurobiological mechanisms that might explain this link; and (3) to integrate these findings and hypotheses within the larger literature implicating frontocingulate dysfunction in depression.

Results from the current meta-analysis indicate that increased pre-treatment rACC activity is a reliable marker of treatment response in depression, which is associated with a large effect size (Cohen's $d$ value: 0.918 ) and has been replicated across 19 studies. Highlighting the robustness of this finding, a link between increased rACC activity and positive antidepressant response has emerged across treatments, including various classes of antidepressant drugs (eg, SSRIs, atypical antidepressants, ketamine), sleep deprivation, and rTMS. The clinical and research implica- 
tions of these findings are substantial. From a clinical perspective, the current meta-analysis indicates that it is possible to identify a priori individuals with a low probability of response to monotherapy, who might benefit from a combination of treatment interventions at the outset. From a research perspective, the findings contribute to a better understanding of mechanisms associated with treatment response. In this context, through an integration of neuropsychological, electrophysiological, and neuroimaging data, I proposed that elevated resting rACC activity may foster better treatment outcome through (1) adaptive forms of reflective, self-focused processing, and (2) adaptive modulations between the DN and TPN, including ability to suppress rACC activation in situations requiring inhibition of emotional responding and recruitment of cognitive control. Future studies will be required to test the hypothesis that low resting rACC activity is associated with deficits in deactivating this DN hub and bringing online the TPN during cognitive tasks, which might foster the emergence of maladaptive emotional and self-focused processing, leading to treatment nonresponse. Along similar lines, the possibility that reduced task-induced rACC deactivation during cognitive and affective challenges represents a floor effect due to low resting rACC activity needs to be carefully investigated.

Although reduced ability to suppress rACC activation during emotional and cognitively demanding tasks has emerged as one of the most consistent findings in the functional neuroimaging literature in depression, several outstanding questions remain. First, because this finding has emerged almost exclusively from currently depressed samples, it is currently unknown whether reduced taskinduced rACC deactivation is a correlate of depression or rather a vulnerability factor. Initial findings of potentiated rACC responses to errors during an executive task in psychiatrically healthy individuals carrying genetic variants linked to increased risk for depression (Holmes et al, 2010) are consistent with the view of a putative vulnerability factor; these findings await replication and studies in additional at-risk samples (eg, unaffected offspring of individuals with depression) will be required for conclusive tests of this hypothesis.

Second, the neurobiological underpinnings of rACC dysfunction remain poorly understood. Initial evidence suggests that reduced task-induced rACC deactivation in MDD might be linked to altered glutamatergic metabolism. Specifically, in a combined fMRI-spectroscopy study, Walter et al (2009) reported that in unmedicated MDD subjects, task-related rACC deactivation during an emotional judgment task correlated with levels of glutamate, the main excitatory neurotransmitter, in the rACC. These findings contrast with data in controls indicating that resting rACC levels of the main inhibitory neutransmitter, $\gamma$-aminobutyric acid (GABA), correlated positively with rACC deactivation during an emotional task (Northoff et al, 2007; Walter et al, 2009). Together, these findings raise the possibility that resting state activity in MDD might shift from a mainly GABA- to glutamate-meditated modulation. In light of an emerging role of glutamate in the pathophysiology of MDD and the mechanism of action of antidepressants (Hashimoto, 2009; Sanacora et al, 2008), future studies are needed to understand the significance of these findings and explore the relevance of these neurochemical abnormalities to treatment response and biased emotional processing in depression.

Third, studies investigating cognitive behavioral therapy have not observed links between rACC activity and treatment outcome (Siegle et al, 2006; see also Konarski et al 2009). The reasons for these discrepancies are not immediately clear, particularly considering that strategies targeting maladaptive cognition and rumination are important components of CBT. In light of the hypothesis that increased resting rACC activity fosters treatment outcome by supporting adaptive forms of rumination, including a mindful, nonevaluative focus, it will be important to test whether this biomarker predicts outcome to mindfulnessbased cognitive therapy, which is an effective treatment for preventing depressive relapse and recurrence (eg, Godfrin and van Heeringen, 2010; Kuyken et al, 2008; Ma and Teasdale, 2004).

Finally, in spite of the robust link between rACC activity and antidepressant response, there are three important weaknesses in this literature that should be addressed. First, with a few exceptions (eg, Korb et al, 2009; Mayberg et al, 2000), most studies have used naturalistic designs without placebo control, likely because of several practical and ethical considerations (eg, expenses of fMRI/PET scans and possible concerns about exposing placebo-treated patients to radioactive PET tracers). Nevertheless, as placebo effects appear in 25-60\% of treated individuals (Quitkin, 1999), 'active' drug responders may in fact be placebo responders. This makes it difficult to differentiate between specific and nonspecific components of treatment response. The report from Korb et al (2009) that increased resting rACC activity predicted antidepressant-but not placebo-response is encouraging, but additional placebo-controlled studies are warranted. In light of findings emerging from the current meta-analysis, EEG methodologies might be especially useful to circumvent some of the practical and ethical considerations mentioned above.

Second, few studies have compared responders with both nonresponders and healthy controls (eg, Pizzagalli et al, 2001), and the author is not aware of any study that has contrasted treatment responders to both nonresponders and healthy controls both before and after treatment in a placebo-controlled design. These contrasts are essential for identifying predictors $v s$ mediators of outcome, as well as for pinpointing the effects of antidepressants on the neural mechanisms under investigation. Third, all studies reviewed have implemented simple univariate statistical models and have not integrated measures of rACC activity with other biological, clinical, genetic, or behavioral data. The development of more advanced, multivariate statistical algorithms might improve our ability to predict outcome on an 
individual basis, which remains a critical priority for the field (Insel, 2009).

\section{ACKNOWLEDGEMENTS}

The author was supported by NIMH Research Grants R01MH68376 and R21MH078979 and by a NARSAD Independent Investigator Award during the preparation of this manuscript. The author is grateful to Dr Daniel Dillon for invaluable comments on this manuscript, and to Sunny Dutra for assistance with the meta-analysis and manuscript preparation.

\section{DISCLOSURE}

Over the past 3 years, Dr Pizzagalli has received research support from ANT North America (Advanced Neurotechnology), consulting fees from ANT and AstraZeneca, and honoraria from AstraZeneca. The author holds a provisional patent (assigned to Harvard University) for the use of EEG measures to predict treatment response in depression (US Provisional Patent Application Serial No. 60/788,656).

\section{REFERENCES}

Abe O, Yamasue H, Kasai K, Yamada H, Aoki S, Inoue H et al (2010). Voxel-based analyses of gray/white matter volume and diffusion tensor data in major depression. Psychiatry Res 181: 64-70.

Aihara M, Ida I, Yuuki N, Oshima A, Kumano H, Takahashi K et al (2007). HPA axis dysfunction in unmedicated major depressive disorder and its normalization by pharmacotherapy correlates with alteration of neural activity in prefrontal cortex and limbic/paralimbic regions. Psychiatry Res 155: 245-256.

Aizenstein HJ, Butters MA, Wu M, Mazurkewicz LM, Stenger VA, Gianaros PJ et al (2009). Altered functioning of the executive control circuit in late-life depression: episodic and persistent phenomena. Am J Geriatr Psychiatry 17: 30-42.

Alexopoulos GS, Kiosses DN, Choi SJ, Murphy CF, Lim KO (2002). Frontal white matter microstructure and treatment response of late-life depression: a preliminary study. Am J Psychiatry 159: 1929-1932.

Alexopoulos GS, Murphy CF, Gunning-Dixon FM, Latoussakis V, Kanellopoulos D, Klimstra S et al (2008). Microstructural white matter abnormalities and remission of geriatric depression. Am J Psychiatry 165: 238-244.

Alexopoulos GS, Schultz SK, Lebowitz BD (2005). Late-life depression: a model for medical classification. Biol Psychiatry 58: 283-289.

Anand A, Li Y, Wang Y, Wu J, Gao S, Bukhari L et al (2005). Antidepressant effect on connectivity of the mood-regulating circuit: an FMRI study. Neuropsychopharmacology 30: 1334-1344.

Anand A, Li Y, Wang Y, Gardner K, Lowe MJ (2007). Reciprocal effects of antidepressant treatment on activity and connectivity of the mood regulating circuit: an FMRI study. J Neuropsychiatry Clin Neurosci 19: 274-282.

Andrews-Hanna JR, Reidler JS, Sepulcre J, Poulin R, Buckner RL (2010). Functional-anatomic fractionation of the brain's default network. Neuron 65: 550-562. An important study suggesting that the rACC is one of the main hubs of the default network and confirming the role of this network in a variety of self-referential functions.

Asada H, Fukuda Y, Tsunoda S, Yamaguchi M, Tonoike M (1999). Frontal midline theta rhythms reflect alternative activation of prefrontal cortex and anterior cingulate cortex in humans. Neurosci Lett 1999: 29-32.

Audenaert K, Goethals I, Van Laere K, Lahorte P, Brans B, Versijpt J et al (2002). SPECT neuropsychological activation procedure with the Verbal Fluency Test in attempted suicide patients. Nucl Med Commun 23: 907-916.

Austin MP, Mitchell P, Goodwin GM (2001). Cognitive deficits in depression: possible implications for functional neuropathology. $\mathrm{Br} J$ Psychiatry 178: 200-206.

Awata S, Ito H, Konno M, Ono S, Kawashima R, Fukuda H et al (1998). Regional cerebral blood flow abnormalities in late-life depression: relation to refractoriness and chronification. Psychiatry Clin Neurosci 52: 97-105.
Awata S, Konno M, Kawashima R, Suzuki K, Sato T, Matsuoka H et al (2002). Changes in regional cerebral blood flow abnormalities in late-life depression following response to electroconvulsive therapy. Psychiatry Clin Neurosci 56: 31-40.

Baddeley A (1998). The central executive: a concept and some misconceptions. $J$ Int Neuropsychol Soc 4: 523-526.

Bae JN, MacFall JR, Krishnan KR, Payne ME, Steffens DC, Taylor WD (2006). Dorsolateral prefrontal cortex and anterior cingulate cortex white matter alterations in late-life depression. Biol Psychiatry 60: 1356-1363.

Bagby RM, Ryder AG, Cristi C (2002). Psychosocial and clinical predictors of response to pharmacotherapy for depression. J Psychiatry Neurosci 27: 250-257.

Ballmaier M, Toga AW, Blanton RE, Sowell ER, Lavretsky H, Peterson J et al (2004). Anterior cingulate, gyrus rectus, and orbitofrontal abnormalities in elderly depressed patients: an MRI-based parcellation of the prefrontal cortex. Am $J$ Psychiatry 161: 99-108.

Beats BC, Sahakian BJ, Levy R (1996). Cognitive performance in tests sensitive to frontal lobe dysfunction in the elderly depressed. Psychol Med 26: 591-603. One of the first studies to show that depression is associated with 'catastrophic' reactions to errors, such as reduced accuracy, immediately after error commission.

Beck AT (2008). The evolution of the cognitive model of depression and its neurobiological correlates. Am J Psychiatry 165: 969-977. An updated review of the influential cognitive model of depression, including its relationship to neurobiological models of the disorder.

Bell-McGinty S, Butters MA, Meltzer CC, Greer PJ, Reynolds III CF, Becker JT (2002). Brain morphometric abnormalities in geriatric depression: long-term neurobiological effects of illness duration. Am J Psychiatry 159: 1424-1427.

Bench CJ, Frackowiak RS, Dolan RJ (1995). Changes in regional cerebral blood flow on recovery from depression. Psychol Med 25: 247-261.

Benedetti F, Bernasconi A, Blasi V, Cadioli M, Colombo C, Falini A et al (2007). Neural and genetic correlates of antidepressant response to sleep deprivation: a functional magnetic resonance imaging study of moral valence decision in bipolar depression. Arch Gen Psychiatry 64: 179-187.

Beste C, Domschke K, Kolev V, Yordanova J, Baffa A, Falkenstein M et al (2010). Functional 5-HT1a receptor polymorphism selectively modulates error-specific subprocesses of performance monitoring. Hum Brain Mapp 31: 621-630.

Biringer E, Mykletun A, Sundet K, Kroken R, Stordal Kl, Lund A (2007). A longitudinal analysis of neurocognitive function in unipolar depression. J Clin Exp Neuropsychol 29: 879-891.

Boes AD, McCormick LM, Coryell WH, Nopoulos P (2008). Rostral anterior cingulate cortex volume correlates with depressed mood in normal healthy children. Biol Psychiatry 63: 391-397.

Boland R, Keller M (2009). Course and outcome of depression. In: IH Gotlib, CL Hammen (eds). Handbook of Depression, 2nd edn. Guilford Press: New York. pp 23-43.

Borenstein M, Rothstein H (1999). A Computer Program for Research Synthesis. BioStat, Inc.: Englewood.

Botvinick MM, Braver TS, Barch DM, Carter CS, Cohen JD (2001). Conflict monitoring and cognitive control. Psychol Rev 108: 624-652.

Brannan SK, Mayberg HS, McGinnis S, Silva JA, Tekell J, Mahurin RK et al (2000). Cingulate metabolism predicts treatment response: a replication. Biol Psychiatry 47: 107S.

Bremner JD, Vythilingam M, Vermetten E, Nazeer A, Adil J, Khan S et al (2002). Reduced volume of orbitofrontal cortex in major depression. Biol Psychiatry 51 273-279.

Brockmann H, Zobel A, Joe A, Biermann K, Scheef L, Schuhmacher A et al (2009). The value of HMPAO SPECT in predicting treatment response to citalopram in patients with major depression. Psychiatry Res 173: 107-112.

Brody AL, Saxena S, Mandelkern MA, Fairbanks LA, Ho ML, Baxter LR (2001). Brain metabolic changes associated with symptom factor improvement in major depressive disorder. Biol Psychiatry 50: 171-178.

Brody AL, Saxena S, Silverman DH, Alborzian S, Fairbanks LA, Phelps ME et al (1999). Brain metabolic changes in major depressive disorder from pre- to posttreatment with paroxetine. Psychiatry Res 91: 127-139.

Broyd SJ, Demanuele C, Debener S, Helps SK, James CJ, Sonuga-Barke EJ (2009). Default-mode brain dysfunction in mental disorders: a systematic review. Neurosci Biobehav Rev 33: 279-296.

Brunovsky M, Bares M, Miloslav K, Stopkova P, Novak T, Krajca V et al (2006). The response-specific changes in EEG tomography (LORETA) after 1 and 4 weeks of treatment in patients with drug-resistant depression. Psychiatrie 10: 71-79.

Buchsbaum MS, Wu J, Siegel BV, Hackett E, Trenary M, Abel L et al (1997). Effect of sertraline on regional metabolic rate in patients with affective disorder. Biol Psychiatry 41: 15-22. 
Buckner RL, Andrews-Hanna JR, Schacter DL (2008). The brain's default network: anatomy, function, and relevance to disease. Ann NY Acad Sci 1124: 1-38. A comprehensive review of the default network literature that covers the network's role in self-referential processes such as introspection, remembering, and planning, in both healthy and diseased states

Bush G, Luu P, Posner Ml (2000). Cognitive and emotional influences in anterior cingulate cortex. Trends Cogn Sci 4: 215-222.

Caetano SC, Kaur S, Brambilla P, Nicoletti M, Hatch JP, Sassi RB et al (2006). Smaller cingulate volumes in unipolar depressed patients. Biol Psychiatry 59: 702-706.

Castaneda AE, Tuulio-Henriksson A, Marttunen M, Suvisaari J, Lonnqvist J (2008). A review on cognitive impairments in depressive and anxiety disorders with a focus on young adults. J Affect Disord 106: 1-27.

Channon S, Green PS (1999). Executive function in depression: the role of performance strategies in aiding depressed and non-depressed participants. J Neurol Neurosurg Psychiatry 66: 162-171.

Chee MW, Choo WC (2004). Functional imaging of working memory after $24 \mathrm{hr}$ of total sleep deprivation. J Neurosci 24: 4560-4567.

Chen CH, Ridler K, Suckling J, Williams S, Fu CH, Merlo-Pich E et al (2007). Brain imaging correlates of depressive symptom severity and predictors of symptom improvement after antidepressant treatment. Biol Psychiatry 62: 407-414.

Chiba T, Kayahara T, Nakano K (2001). Efferent projections of infralimbic and prelimbic areas of the medial prefrontal cortex in the Japanese monkey, Macaca fuscata. Brain Res 888: 83-101.

Clark CP, Brown GG, Archibald SL, Fennema-Notestine C, Braun DR, Thomas LS et al (2006). Does amygdalar perfusion correlate with antidepressant response to partial sleep deprivation in major depression? Psychiatry Res 146: 43-51.

Clark CP, Frank LR, Brown GG (2001). Sleep deprivation, EEG, and functional MRI in depression: preliminary results. Neuropsychopharmacology 25: S79-S84.

Coffey CE, Wilkinson WE, Weiner RD, Parashos IA, Djang WT, Webb MC et al (1993). Quantitative cerebral anatomy in depression. A controlled magnetic resonance imaging study. Arch Gen Psychiatry 50: 7-16.

Cohen J (1988). Statistical Power Analysis for the Behavioral Sciences. Erlbaum Associates: Hillsdale, $\mathrm{NJ}$

Compton RJ, Lin M, Vargas G, Carp J, Fineman SL, Quandt LC (2008a). Error detection and posterror behavior in depressed undergraduates. Emotion 8: $58-67$

Conway CR, Sheline YI, Chibnall JT, George MS, Fletcher JW, Mintun MA (2006). Cerebral blood flow changes during vagus nerve stimulation for depression. Psychiatry Res 146: 179-184.

Corbetta M, Shulman GL (2002). Control of goal-directed and stimulus-driven attention in the brain. Nat Rev Neurosci 3: 201-215.

Costafreda SG, Chu C, Ashburner J, Fu CH (2009a). Prognostic and diagnostic potential of the structural neuroanatomy of depression. PLoS One 4: e6353.

Costafreda SG, Khanna A, Mourao-Miranda J, Fu CH (2009b). Neural correlates of sad faces predict clinical remission to cognitive behavioural therapy in depression. NeuroReport 20: 637-641.

Crane C, Barnhofer T, Visser C, Nightingale H, Williams JM (2007). The effects of analytical and experiential rumination on autobiographical memory specificity in individuals with a history of major depression. Behav Res Ther 45: 3077-3087.

Cullen KR, Klimes-Dougan B, Muetzel R, Mueller BA, Camchong J, Houri A et al (2010). Altered white matter microstructure in adolescents with major depression: a preliminary study. J Am Acad Child Adolesc Psychiatry 49: 173-183.

Davidson RJ, Irwin W, Anderle MJ, Kalin NH (2003). The neural substrates of affective processing in depressed patients treated with venlafaxine. Am J Psychiatry 160: 64-75.

Davidson RJ, Pizzagalli D, Nitschke JB, Putnam K (2002). Depression: perspectives from affective neuroscience. Annu Rev Psychol 53: 545-574.

Davies J, Lloyd KR, Jones IK, Barnes A, Pilowsky LS (2003). Changes in regional cerebral blood flow with venlafaxine in the treatment of major depression. Am J Psychiatry 160: 374-376.

Davis RN, Nolen-Hoeksema S (2000). Cognitive inflexibility among ruminators and nonruminators. Cognitive Ther Res 24: 699-711.

Den Hartog HM, Derix MM, Van Bemmel AL, Kremer B, Jolles J (2003). Cognitive functioning in young and middle-aged unmedicated out-patients with major depression: testing the effort and cognitive speed hypotheses. Psychol Med 33: 1443-1451.

DeRubeis RJ, Hollon SD, Amsterdam JD, Shelton RC, Young PR, Salomon RM et al (2005). Cognitive therapy vs medications in the treatment of moderate to severe depression. Arch Gen Psychiatry 62: 409-416.

Devinsky O, Morrell MJ, Vogt BA (1995). Contributions of anterior cingulate cortex to behaviour. Brain 118: 279-306.

Dillon DG., Pizzagalli DA (2007). Inhibition of action, thought, and emotion: a selective neurobiological review. Appl Prev Psychol 12: 99-114.
Drevets WC, Raichle ME (1998). Reciprocal suppression of regional cerebral blood flow during emotional versus higher cognitive process: implications for interaction between cognition and emotion. Cogn Emot 12: 353-385.

Dunkin JJ, Leuchter AF, Cook IA, Kasl-Godley JE, Abrams M, RosenbergThompson S (2000). Executive dysfunction predicts nonresponse to fluoxetine in major depression. J Affect Disord 60: 13-23.

Ebert D, Feistel H, Barocka A (1991). Effects of sleep deprivation on the limbic system and the frontal lobes in affective disorders: a study with Tc-99m-HMPAO SPECT. Psychiatry Res 40: 247-251. The first functional neuroimaging study to show that increased resting perfusion in the rACC before treatment predicts favorable response to sleep depreivation.

Ebert D, Feistel H, Barocka A, Kaschka W (1994). Increased limbic blood flow and total sleep deprivation in major depression with melancholia. Psychiatry Res 55: 101-109.

Elliott R, Baker SC, Rogers RD, O'Leary DA, Paykel ES, Frith CD et al (1997a). Prefrontal dysfunction in depressed patients performing a complex planning task: a study using positron emission tomography. Psychol Med 27: 931-942.

Elliott R, Sahakian BJ, Herrod JJ, Robbins TW, Paykel ES (1997b). Abnormal response to negative feedback in unipolar depression: evidence for a diagnosis specific impairment. J Neurol Neurosurg Psychiatry 63: 74-82. Among the first studies to show that poor behavioral performance after negative feedback was characteristic of depression and persisted after recovery, highlighting a possible trait-related vulnerability.

Elliott R, Sahakian BJ, McKay AP, Herrod JJ, Robbins TW, Paykel ES (1996). Neuropsychological impairments in unipolar depression: the influence of perceived failure on subsequent performance. Psychol Med 26: 975-989.

Elliott R, Rubinsztein JS, Sahakian BJ, Dolan RJ (2002). The neural basis of mood-congruent processing biases in depression. Arch Gen Psychiatry 59: 597-604.

Etkin A, Egner T, Peraza DM, Kandel ER, Hirsch J (2006). Resolving emotional conflict: a role for the rostral anterior cingulate cortex in modulating activity in the amygdala. Neuron 51: 871-882.

Eugene F, Joormann J, Cooney RE, Atlas LY, Gotlib IH (2010). Neural correlates of inhibitory deficits in depression. Psychiatry Res 181: 30-35.

Fales CL, Barch DM, Rundle MM, Mintun MA, Mathews J, Snyder AZ et al (2009). Antidepressant treatment normalizes hypoactivity in dorsolateral prefrontal cortex during emotional interference processing in major depression. J Affect Disord 112: 206-211.

Fales CL, Barch DM, Rundle MM, Mintun MA, Snyder AZ, Cohen JD et al (2008). Altered emotional interference processing in affective and cognitive-control brain circuitry in major depression. Biol Psychiatry 63: 377-384.

Fallgatter AJ, Herrmann MJ, Roemmler J, Ehlis AC, Wagener A, Heidrich A et al (2004). Allelic variation of serotonin transporter function modulates the brain electrical response for error processing. Neuropsychopharmacology 29: 15061511.

Feenstra BW, Holsheimer J (1979). Dipole-like neuronal sources of theta rhythm in dorsal hippocampus, dentate gyrus and cingulated cortex of the urethaneanesthetized rat. Electroencephalogr Clin Neurophysiol 47: 532-538.

Fitzgerald PB, Srithiran A, Benitez J, Daskalakis ZZ, Oxley TJ, Kulkarni J et al (2008). An fMRI study of prefrontal brain activation during multiple tasks in patients with major depressive disorder. Hum Brain Mapp 29: 490-501.

Fletcher PC, McKenna PJ, Frith CD, Grasby PM, Friston KJ, Dolan RJ (1998). Brain activations in schizophrenia during a graded memory task studied with functional neuroimaging. Arch Gen Psychiatry 55: 1001-1008.

Fox MD, Snyder AZ, Vincent JL, Corbetta M, Van Essen DC, Raichle ME (2005). The human brain is intrinsically organized into dynamic, anticorrelated functional networks. Proc Natl Acad Sci USA 102: 9673-9678. Among the first demonstrations that the default network and the task-positive networks are temporally anticorrelated during resting states.

Freed PJ, Yanagihara TK, Hirsch J, Mann JJ (2009). Neural mechanisms of grief regulation. Biol Psychiatry 66: 33-40.

Frodl T, Jager M, Born C, Ritter S, Kraft E, Zetzsche T et al (2008a). Anterior cingulate cortex does not differ between patients with major depression and healthy controls, but relatively large anterior cingulate cortex predicts a good clinical course. Psychiatry Res 163: 76-83.

Frodl T, Reinhold E, Koutsouleris N, Reiser M, Meisenzahl EM (2010). Interaction of childhood stress with hippocampus and prefrontal cortex volume reduction in major depression. J Psychiatr Res 44: 799-807.

Frodl TS, Koutsouleris N, Bottlender R, Born C, Jager M, Scupin I et al (2008b). Depression-related variation in brain morphology over 3 years: effects of stress? Arch Gen Psychiatry 65: 1156-1165. A 3-year prospective study showing a greater decline in rACC and DLPFC volume in depressed individuals relative to healthy controls. This difference was most pronounced when considering individuals whose depression did not remit over the studied period 
George MS, Ketter TA, Parekh PI, Rosinsky N, Ring HA, Pazzaglia PJ et al (1997). Blunted left cingulate activation in mood disorder subjects during a response interference task (the Stroop). J Neuropsychiatry Clin Neurosci 9: 55-63.

Godfrin KA, van Heeringen C (2010). The effects of mindfulness-based cognitive therapy on recurrence of depressive episodes, mental health and quality of life: a randomized controlled study. Behav Res Ther 48: 738-746.

Goeleven E, De Raedt R, Baert S, Koster EH (2006). Deficient inhibition of emotional information in depression. J Affect Disord 93: 149-157.

Goodwin GM, Austin MP, Dougall N, Ross M, Murray C, O'Carroll RE et al (1993). State changes in brain activity shown by the uptake of $99 \mathrm{mTc}$-exametazime with single photon emission tomography in major depression before and after treatment. J Affect Disord 29: 243-253.

Gorlyn M, Keilp JG, Grunebaum MF, Taylor BP, Oquendo MA, Bruder GE et al (2008). Neuropsychological characteristics as predictors of SSRI treatment response in depressed subjects. J Neural Transm 115: 1213-1219.

Gotlib $\Vdash$, Joormann J (2010). Cognition and depression: current status and future directions. Annu Rev Clin Psychol 6: 285-312. A comprehensive review of emotional processing biases and cognitive dysfunctions in depression.

Gotlib IH, Krasnoperova E, Yue DN, Joormann J (2004). Attentional biases for negative interpersonal stimuli in clinical depression. J Abnorm Psychol 113: 121135.

Greicius MD, Krasnow B, Reiss AL, Menon V (2003). Functional connectivity in the resting brain: a network analysis of the default mode hypothesis. Proc Natl Acad Sci USA 100: 253-258.

Greenberg PE, Kessler RC, Birnbaum HG, Leong SA, Lowe SW, Berglund PA et al (2003). The economic burden of depression in the United States: how did it change between 1990 and 2000? J Clin Psychiatry 64: 1465-1475.

Grimm S, Boesiger P, Beck J, Schuepbach D, Bermpohl F, Walter M et al (2009). Altered negative BOLD responses in the default-mode network during emotion processing in depressed subjects. Neuropsychopharmacology 34: 932-843. An important fMRI study showing that major depression is characterized by reduced task-induced RACC deactivation, particularly with increasing depression severity and feelings of hopelessness.

Gunning FM, Cheng J, Murphy CF, Kanellopoulos D, Acuna J, Hoptman MJ et al (2009). Anterior cingulate cortical volumes and treatment remission of geriatric depression. Int J Geriatr Psychiatry 24: 829-836.

Gusnard DA, Akbudak E, Shulman GL, Raichle ME (2001). Medial prefrontal cortex and self-referential mental activity: relation to a default mode of brain function. Proc Natl Acad Sci USA 98: 4259-4264.

Halari R, Simic M, Pariante CM, Papadopoulos A, Cleare A, Brammer M et al (2009). Reduced activation in lateral prefrontal cortex and anterior cingulate during attention and cognitive control functions in medication-naive adolescents with depression compared to controls. J Child Psychol Psychiatry 50: 307-316.

Halloran E, Prentice N, Murray CL, O'Carroll RE, Glabus MF, Goodwin GM et al (1999). Follow-up study of depression in the elderly. Clinical and SPECT data. $\mathrm{Br}$ $J$ Psychiatry 175: 252-258.

Hammar A, Ardal G (2009). Cognitive functioning in major depression-a summary. Front Hum Neurosci 3: 26.

Hammar A, Sorensen L, Ardal G, Oedegaard KJ, Kroken R, Roness A et al (2009). Enduring cognitive dysfunction in unipolar major depression: a test-retest study using the Stroop paradigm. Scand J Psychol 51: 304-308.

Harvey PO, Fossati P, Pochon JB, Levy R, Lebastard G, Lehericy S et al (2005). Cognitive control and brain resources in major depression: an fMRI study using the n-back task. Neuroimage 26: 860-869.

Hashimoto K (2009). Emerging role of glutamate in the pathophysiology of major depressive disorder. Brain Res Rev 61: 105-123.

Henry ME, Schmidt ME, Matochik JA, Stoddard EP, Potter WZ (2001). The effects of ECT on brain glucose: a pilot FDG PET study. J ECT 17: 33-40.

Holma KM, Melartin TK, Haukka J, Holma IA, Sokero TP, Isometsä ET (2010). Incidence and predictors of suicide attempts in DSM-IV major depressive disorder: a five-year prospective study. Am J Psychiatry 167: 801-808.

Holmes AJ, Bogdan R, Pizzagalli DA (2010). Serotonin transporter genotype and action monitoring dysfunction: a possible substrate underlying increased vulnerability to depression. Neuropsychopharmacology 35: 1186-1197. An fMRI study showing that psychiatrically healthy individuals carrying genetic variants previously linked to depression vulnerability are characterized by behavioral (eg, decreased post-error behavioral adjustments) and neural (eg, potentiated rACC responses to errors) abnormalities similar to those seen in depressed individuals.

Holmes AJ, MacDonald III A, Carter CS, Barch DM, Andrew Stenger V, Cohen JD (2005). Prefrontal functioning during context processing in schizophrenia and major depression: an event-related fMRI study. Schizophr Res 76: 199-206.

Holmes AJ, Pizzagalli DA (2007). Task feedback effects on conflict monitoring and executive control: relationship to subclinical measures of depression. Emotion 7: 68-76.
Holmes AJ, Pizzagalli DA (2008a). Response conflict and frontocingulate dysfunction in unmedicated participants with major depression. Neuropsychologia 46: 2904-2913.

Holmes AJ, Pizzagalli DA (2008b). Spatiotemporal dynamics of error processing dysfunctions in major depressive disorder. Arch Gen Psychiatry 65: 179-188. This study demonstrated a rapid ( $80 \mathrm{~ms}$ post-error) and potentiated rACC responses to errors in depressed participants relative to controls, followed shortly thereafter $(472 \mathrm{~ms}$ post-error) by reduced ability to recruit dorsolateral prefrontal cortex regions that implement cognitive control.

Holthoff VA, Beuthien-Baumann B, Pietrzyk U, Pinkert J, Oehme L, Franke WG et al (1999). Regionale Funktionsstörung bei der Depression Hirn-SPECT zur Verlaufskontrolle [Changes in regional cerebral perfusion in depression. SPECT monitoring of response to treatment]. Nervenarzt 70: 620-626.

Holthoff VA, Beuthien-Baumann B, Zundorf G, Triemer A, Ludecke S, Winiecki P et al (2004). Changes in brain metabolism associated with remission in unipolar major depression. Acta Psychiatr Scand 110: 184-194.

Hooley JM, Gruber SA, Parker HA, Guillaumot J, Rogowska J, Yurgelun-Todd DA (2009). Cortico-limbic response to personally challenging emotional stimuli after complete recovery from depression. Psychiatry Res 172: 83-91.

Hornig M, Mozley PD, Amsterdam JD (1997). HMPAO SPECT brain imaging in treatment-resistant depression. Prog Neuropsychopharmacol Biol Psychiatry 21 1097-1114.

Hugdahl K, Rund BR, Lund A, Asbjornsen A, Egeland J, Ersland L et al (2004). Brain activation measured with $\mathrm{fMRI}$ during a mental arithmetic task in schizophrenia and major depression. Am J Psychiatry 161: 286-293.

Insel TR (2009). Translating scientific opportunity into public health impact: a strategic plan for research on mental illness. Arch Gen Psychiatry 66: 128-133. An opinion piece summarizing the NIMH perspective on the need for new interventions based on a personalized approach to mental illness.

Ishizaki J, Yamamoto H, Takahashi T, Takeda M, Yano M, Mimura M (2008). Changes in regional cerebral blood flow following antidepressant treatment in late-life depression. Int J Geriatr Psychiatry 23: 805-811.

Joe AY, Tielmann T, Bucerius J, Reinhardt MJ, Palmedo H, Maier W et al (2006). Response-dependent differences in regional cerebral blood flow changes with citalopram in treatment of major depression. J Nucl Med 47: 1319-1325.

Johansen-Berg H, Gutman DA, Behrens TE, Matthews PM, Rushworth MF, Katz E et al (2008). Anatomical connectivity of the subgenual cingulate region targeted with deep brain stimulation for treatment-resistant depression. Cereb Cortex 18: 1374-1383.

Jones NP, Siegle GJ, Muelly ER, Haggerty A, Ghinassi F (2010). Poor performance on cognitive tasks in depression: doing too much or not enough? Cogn Affect Behav Neurosci 10: 129-140.

Joormann J, Gotlib IH (2010). Emotion regulation in depression: relation to cognitive inhibition. Cogn Emot 24: 281-298.

Keedwell P, Drapier D, Surguladze S, Giampietro V, Brammer M, Phillips M (2009). Neural markers of symptomatic improvement during antidepressant therapy in severe depression: subgenual cingulate and visual cortical responses to sad, but not happy, facial stimuli are correlated with changes in symptom score. J Psychopharmacol 23: 775-788

Keedwell PA, Drapier D, Surguladze S, Giampietro V, Brammer M, Phillips M (2010). Subgenual cingulate and visual cortex responses to sad faces predict clinical outcome during antidepressant treatment for depression. J Affect Disord 120: 120-125.

Kelly AM, Uddin LQ, Biswal BB, Castellanos FX, Milham MP (2008). Competition between functional brain networks mediates behavioral variability. Neuroimage 39: $527-537$.

Kennedy DP, Redcay E, Courchesne E (2006). Failing to deactivate: resting functional abnormalities in autism. Proc Natl Acad Sci USA 103: 8275-8280.

Kennedy SH, Evans KR, Kruger S, Mayberg HS, Meyer JH, McCann S et al (2001). Changes in regional brain glucose metabolism measured with positron emission tomography after paroxetine treatment of major depression. Am J Psychiatry 158: 899-905.

Kennedy SH, Konarski JZ, Segal ZV, Lau MA, Bieling PJ, Mclntyre RS et al (2007). Differences in brain glucose metabolism between responders to CBT and venlafaxine in a 16-week randomized controlled trial. Am J Psychiatry 164: 778-788.

Kerns JG, Cohen JD, MacDonald III AW, Cho RY, Stenger VA, Carter CS (2004). Anterior cingulate conflict monitoring and adjustments in control. Science 303: 1023-1026. This work demonstrated that ACC activation during high conflict trials predicts recruitment of prefrontal cortical regions implicated in cognitive control and adaptive behavioral adjustments.

Kessing LV (1998). Cognitive impairment in the euthymic phase of affective disorder. Psychol Med 28: 1027-1038.

Kessler RC, Berglund P, Demler O, Jin R, Merikangas KR, Walters EE (2005). Lifetime prevalence and age-of-onset distributions of DSM-IV disorders in the National Comorbidity Survey Replication. Arch Gen Psychiatry 62: 593-602. 
Ketter TA, Kimbrell TA, George MS, Willis MW, Benson BE, Danielson A et al (1999). Baseline cerebral hypermetabolism associated with carbamazepine response, and hypometabolism with nimodipine response in mood disorders. Biol Psychiatry 46: 1364-1374.

Kito S, Fujita K, Koga Y (2008a). Changes in regional cerebral blood flow after repetitive transcranial magnetic stimulation of the left dorsolateral prefrontal cortex in treatment-resistant depression. J Neuropsychiatry Clin Neurosci 20: 74-80.

Kito S, Fujita K, Koga Y (2008b). Regional cerebral blood flow changes after lowfrequency transcranial magnetic stimulation of the right dorsolateral prefrontal cortex in treatment-resistant depression. Neuropsychobiology 58: 29-36.

Kohn Y, Freedman N, Lester H, Krausz Y, Chisin R, Lerer B et al (2007). 99mTcHMPAO SPECT study of cerebral perfusion after treatment with medication and electroconvulsive therapy in major depression. J Nucl Med 48: 1273-1278.

Konarski JZ, Kennedy SH, Segal ZV, Lau MA, Bieling PJ, Mclntyre RS et al (2009). Predictors of nonresponse to cognitive behavioural therapy or venlafaxine using glucose metabolism in major depressive disorder. J Psychiatry Neurosci 34: 175-180.

Koolschijn PC, van Haren NE, Lensvelt-Mulders GJ, Hulshoff Pol HE, Kahn RS (2009). Brain volume abnormalities in major depressive disorder: a meta-analysis of magnetic resonance imaging studies. Hum Brain Mapp 30: 3719-3735. A comprehensive meta-analysis of brain volume abnormalities in major depression.

Korb AS, Hunter AM, Cook IA, Leuchter AF (2009). Rostral anterior cingulate cortex theta current density and response to antidepressants and placebo in major depression. Clin Neurophysiol 120: 1313-1319. The first double-blind, placebo-controlled EEG study to show that increased resting $\mathrm{rACC}$ activity before treatment predicts a positive response to antidepressant drugs but not placebo.

Koster EH, De Raedt R, Goeleven E, Franck E, Crombez G (2005). Moodcongruent attentional bias in dysphoria: maintained attention to and impaired disengagement from negative information. Emotion 5: 446-455.

Kuehner C, Weber I (1999). Responses to depression in unipolar depressed patients: an investigation of Nolen-Hoeksema's response styles theory. Psychol Med 29: 1232-1333.

Kumar A, Jin Z, Bilker W, Udupa J, Gottlieb G (1998). Late-onset minor and major depression: early evidence for common neuroanatomical substrates detected by using MRI. Proc Natl Acad Sci USA 95: 7654-7658.

Kuyken W, Byford S, Taylor RS, Watkins E, Holden E, White K et al (2008). Mindfulness-based cognitive therapy to prevent relapse in recurrent depression. J Consult Clin Psychol 76: 966-978.

Langenecker SA, Kennedy SE, Guidotti LM, Briceno EM, Own LS, Hooven T et al (2007). Frontal and limbic activation during inhibitory control predicts treatment response in major depressive disorder. Biol Psychiatry 62: 1272-1280.

Langguth B, Wiegand R, Kharraz A, Landgrebe M, Marienhagen J, Frick U et al (2007). Pre-treatment anterior cingulate activity as a predictor of antidepressant response to repetitive transcranial magnetic stimulation (rTMS). Neuro Endocrinol Lett 28: 633-638.

Lau MA, Christensen BK, Hawley LL, Gemar MS, Segal ZV (2007). Inhibitory deficits for negative information in persons with major depressive disorder. Psychol Med 37: 1249-1259.

Lavretsky H, Ballmaier M, Pham D, Toga A, Kumar A (2007). Neuroanatomical characteristics of geriatric apathy and depression: a magnetic resonance imaging study. Am J Geriatr Psychiatry 15: 386-394.

Leh SE, Petrides M, Strafella AP (2010). The neural circuitry of executive functions in healthy subjects and Parkinson's disease. Neuropsychopharmacology 35: 7085. A comprehensive review of the neural circuitry of executive functions.

Leung KK, Lee TM, Wong MM et al. (2009). Neural correlates of attention biases of people with major depressive disorder: a voxel-based morphometric study. Psychol Med 39: 1097-1106. A voxel-based morphometric study showing that reduced rACC volume is associated with attentional biases toward negative words.

Levens SM, Muhtadie L, Gotlib $\boxplus$ (2009). Rumination and impaired resource allocation in depression. J Abnorm Psychol 118: 757-766.

Li CS, Yan P, Bergquist KL, Sinha R (2007a). Greater activation of the 'default' brain regions predicts stop signal errors. Neuroimage 38: 640-648.

Li CT, Lin CP, Chou KH, Chen IY, Hsieh JC, Wu CL et al (2010). Structural and cognitive deficits in remitting and non-remitting recurrent depression: a voxelbased morphometric study. Neuroimage 50: 347-356.

Li L, Ma N, Li Z, Tan L, Liu J, Gong G et al (2007b). Prefrontal white matter abnormalities in young adult with major depressive disorder: a diffusion tensor imaging study. Brain Res 1168: 124-128.

Lieberman MD, Berkman ET, Wager TD (2009). Correlations in social neuroscience aren't voodoo: commentary on Vul et al. (2009). Perspect Psychol Sci 4: 299-307.
Lipsey MW, Wilson DB (2001). The way in which intervention studies have 'personality' and why it is important to meta-analysis. Eval Health Prof 24: 236-254.

Little JT, Ketter TA, Kimbrell TA, Dunn RT, Benson BE, Willis MW et al (2005). Bupropion and venlafaxine responders differ in pretreatment regional cerebral metabolism in unipolar depression. Biol Psychiatry 57: 220-228.

Lopez AD, Mathers CD, Ezzati M, Jamison DT, Murray CJ (2006). Global and regional burden of disease and risk factors, 2001: systematic analysis of population health data. Lancet 367: 1747-1757.

Lorenzetti V, Allen NB, Fornito A, Yucel M (2009). Structural brain abnormalities in major depressive disorder: a selective review of recent MRI studies. J Affect Disord 117: 1-17.

Luria AR (1971). Memory disturbances in local brain lesions. Neuropsychologia 9: 367-375.

Lustig C, Snyder AZ, Bhakta M, O’Brien KC, McAvoy M, Raichle ME et al (2003). Functional deactivations: change with age and dementia of the Alzheimer type. Proc Natl Acad Sci USA 100: 14504-14509.

Ma SH, Teasdale JD (2004). Mindfulness-based cognitive therapy for depression: replication and exploration of differential relapse prevention effects. J Consult Clin Psychol 72: 31-40

Ma N, Li L, Shu N, Liu J, Gong G, He Z et al (2007). White matter abnormalities in first-episode, treatment-naive young adults with major depressive disorder. Am J Psychiatry 164: 823-826.

Macdonald III AW, Cohen JD, Stenger VA, Carter CS (2000). Dissociating the role of the dorsolateral prefrontal and anterior cingulate cortex in cognitive control. Science 288: 1835-1838

Mak AK, Wong MM, Han SH, Lee TM (2009). Gray matter reduction associated with emotion regulation in female outpatients with major depressive disorder: a voxelbased morphometry study. Prog Neuropsychopharmacol Biol Psychiatry 33: 1184-1190. A morphometric study providing empirical evidence that reduced rACC volume is associated with a diminished ability to downregulate negative (but not positive) emotions.

Mannell MV, Franco AR, Calhoun VD, Canive JM, Thoma RH, Mayer AR (2010). Resting state and task-induced deactivation: a methodological comparison in patients with schizophrenia and healthy controls. Hum Brain Mapp 31: 424-437.

Margulies DS, Kelly AM, Uddin LQ, Biswal BB, Castellanos FX, Milham MP (2007). Mapping the functional connectivity of anterior cingulate cortex. Neuroimage 37: 579-588.

Marquand AF, Mourao-Miranda J, Brammer MJ, Cleare AJ, Fu CH (2008). Neuroanatomy of verbal working memory as a diagnostic biomarker for depression. NeuroReport 19: 1507-1511.

Matsuo K, Glahn DC, Peluso MA, Hatch JP, Monkul ES, Najt P et al (2007). Prefrontal hyperactivation during working memory task in untreated individuals with major depressive disorder. Mol Psychiatry 12: 158-166.

Mayberg HS (2003). Modulating dysfunctional limbic-cortical circuits in depression: towards development of brain-based algorithms for diagnosis and optimised treatment. Br Med Bull 65: 193-207.

Mayberg HS, Brannan SK, Mahurin RK, Jerabek PA, Brickman JS, Tekell JL et al (1997). Cingulate function in depression: a potential predictor of treatment response. NeuroReport 8: 1057-1061. The first functional neuroimaging study to show that increased resting cerebral blood flow in the rACC before treatment predicts favorable response to a variety of antidepressant drugs

Mayberg HS, Brannan SK, Tekell JL, Silva JA, Mahurin RK, McGinnis S et al (2000). Regional metabolic effects of fluoxetine in major depression: serial changes and relationship to clinical response. Biol Psychiatry 48: 830-843.

Mayberg HS, Silva JA, Brannan SK, Tekell JL, Mahurin RK, McGinnis S et al (2002). The functional neuroanatomy of the placebo effect. Am J Psychiatry 159: 728-737.

McCormick LM, Boles Ponto LL, Pierson RK, Johnson HJ, Magnotta V, Brumm MC (2007). Metabolic correlates of antidepressant and antipsychotic response in patients with psychotic depression undergoing electroconvulsive therapy. J ECT 23: 265-273.

McKiernan KA, Kaufman JN, Kucera-Thompson J, Binder JR (2003). A parametric manipulation of factors affecting task-induced deactivation in functional neuroimaging. J Cogn Neurosci 15: 394-408.

Milak MS, Parsey RV, Lee L, Oquendo MA, Olvet DM, Eipper F et al (2009). Pretreatment regional brain glucose uptake in the midbrain on PET may predict remission from a major depressive episode after three months of treatment. Psychiatry Res 173: 63-70.

Miller EK, Cohen JD (2001). An integrative theory of prefrontal cortex function. Annu Rev Neurosci 24: 167-202.

Mitterschiffthaler MT, Williams SC, Walsh ND, Cleare AJ, Donaldson C, Scott J et al (2008). Neural basis of the emotional Stroop interference effect in major depression. Psychol Med 38: 247-256. 
Mottaghy FM, Keller CE, Gangitano M, Ly J, Thall M, Parker JA et al (2002). Correlation of cerebral blood flow and treatment effects of repetitive transcrania magnetic stimulation in depressed patients. Psychiatry Res 115: 1-14.

Mulert C, Juckel G, Brunnmeier M, Karch S, Leicht G, Mergl R et al (2007a). Prediction of treatment response in major depression: integration of concepts. J Affect Disord 98: 215-225.

Mulert C, Juckel G, Brunnmeier M, Karch S, Leicht G, Mergl R et al (2007b). Rostral anterior cingulate cortex activity in the theta band predicts response to antidepressive medication. Clin EEG Neurosci 38: 78-81.

Murphy CF, Gunning-Dixon FM, Hoptman MJ, Lim KO, Ardekani B, Shields JK et al (2007). White-matter integrity predicts stroop performance in patients with geriatric depression. Biol Psychiatry 61: 1007-1010.

Murphy FC, Michael A, Robbins TW, Sahakian BJ (2003). Neuropsychological impairment in patients with major depressive disorder: the effects of feedback on task performance. Psychol Med 33: 455-467.

Nadeau SE, McCoy KJ, Crucian GP, Greer RA, Rossi F, Bowers D et al (2002). Cerebral blood flow changes in depressed patients after treatment with repetitive transcranial magnetic stimulation: evidence of individual variability. Neuropsychiatry Neuropsychol Behav Neurol 15: 159-175.

Navarro V, Gasto C, Lomena F, Torres X, Mateos JJ, Portella MJ et al (2004). Prognostic value of frontal functional neuroimaging in late-onset severe major depression. Br J Psychiatry 184: 306-311.

Nichols TE, Poline J-B (2009). Commentary on Vul et al.'s (2009) 'Puzzlingly high correlations in fMRI studies of emotion, personality, and social cognition'. Perspect Psychol Sci 4: 291-293.

Nierenberg AA (2003). Predictors of response to antidepressants general principles and clinical implications. Psychiatr Clin North Am 26: 345-352.

Nobler MS, Oquendo MA, Kegeles LS, Malone KM, Campbell CC, Sackeim HA et al (2001). Decreased regional brain metabolism after ECT. Am J Psychiatry 158: $305-308$.

Nobuhara K, Okugawa G, Sugimoto T, Minami T, Tamagaki C, Takase Ket al (2006). Frontal white matter anisotropy and symptom severity of late-life depression: a magnetic resonance diffusion tensor imaging study. I Neurol Neurosurg Psychiatry 77: 120-122.

Nolen-Hoeksema S (1991). Responses to depression and their effects on the duration of depressive episodes. J Abnorm Psychol 100: 569-582.

Nolen-Hoeksema S, Wisco BE, Lyubomirsky S (2008). Rethinking rumination. Perspect Psychol Sci 3: 400-424. A recent reconceptualization of the role of rumination in depression

Northoff G, Heinzel A, de Greck M, Bermpohl F, Dobrowolny H, Panksepp J (2006). Self-referential processing in our brain-a meta-analysis of imaging studies on the self. Neuroimage 31: 440-457.

Northoff G, Walter M, Schulte RF, Beck J, Dydak U, Henning A et al (2007). GABA concentrations in the human anterior cingulate cortex predict negative BOLD responses in fMRI. Nat Neurosci 10: 1515-1517.

Ochsner KN, Gross JJ (2005). The cognitive control of emotion. Trends Cogn Sci 9 242-249.

Ochsner KN, Hughes B, Robertson ER, Cooper JC, Gabrieli JD (2009). Neural systems supporting the control of affective and cognitive conflicts. J Cogn Neurosci 21: 1842-1855.

Okada G, Okamoto Y, Morinobu S, Yamawaki S, Yokota N (2003). Attenuated left prefrontal activation during a verbal fluency task in patients with depression. Neuropsychobiology 47: 21-26.

Orwin RG (1983). A fail safe $\mathrm{N}$ for effect size in meta-analysis. J Educ Stat 8 157-159.

Paelecke-Habermann Y, Pohl J, Leplow B (2005). Attention and executive functions in remitted major depression patients. J Affect Disord 89: 125-135.

Pallesen KJ, Brattico E, Bailey CJ, Korvenoja A, Gjedde A (2009). Cognitive and emotional modulation of brain default operation. $J$ Cogn Neurosci 21 1065-1080.

Palomero-Gallagher N, Mohlberg H, Zilles K, Vogt B (2008). Cytology and receptor architecture of human anterior cingulate cortex. J Comp Neurol 508: 906-926.

Paradiso S, Lamberty GJ, Garvey MJ, Robinson RG (1997). Cognitive impairment in the euthymic phase of chronic unipolar depression. J Nerv Ment Dis 185 748-754.

Persson J, Lustig C, Nelson JK, Reuter-Lorenz PA (2007). Age differences in deactivation: a link to cognitive control? J Cogn Neurosci 19: 1021-1032.

Phan KL, Taylor SF, Welsh RC, Ho SH, Britton JC, Liberzon I (2004). Neural correlates of individual ratings of emotional salience: a trial-related fMRI study. Neuroimage 21: 768-780.

Pizzagalli D, Pascual-Marqui RD, Nitschke JB, Oakes TR, Larson CL, Abercrombie $\mathrm{HC}$ et al (2001). Anterior cingulate activity as a predictor of degree of treatment response in major depression: evidence from brain electrical tomography analysis. Am J Psychiatry 158: 405-415. The first EEG study to show that resting rACC activity predicts antidepressant response in individuals with MDD.
Pizzagalli DA, Oakes TR, Davidson RJ (2003). Coupling of theta activity and glucose metabolism in the human rostral anterior cingulated cortex: an EEG/PET study of normal and depressed subjects. Psychophysiology 40: 939-949.

Pizzagalli DA, Peccoralo LA, Davidson RJ, Cohen JD (2006). Resting anterior cingulate activity and abnormal responses to errors in subjects with elevated depressive symptoms: a 128-channel EEG study. Hum Brain Mapp 27: 185-201.

Poldrack RA, Mumford JA (2009). Independence in ROI analysis: where is the voodoo? Soc Cogn Affect Neurosci 4: 208-213.

Polli FE, Barton JJ, Cain MS, Thakkar KN, Rauch SL, Manoach DS (2005). Rostral and dorsal anterior cingulate cortex make dissociable contributions during antisaccade error commission. Proc Natl Acad Sci USA 102: 15700-15705.

Porter RJ, Gallagher P, Thompson JM, Young AH (2003). Neurocognitive impairment in drug-free patients with major depressive disorder. $\mathrm{Br} J$ Psychiatry 182: 214-220.

Purcell R, Maruff P, Kyrios M, Pantelis C (1997). Neuropsychological function in young patients with unipolar major depression. Psychol Med 27: 1277-1285.

Quitkin FM (1999). Placebos, drug effects, and study design: a clinician's guide. Am J Psychiatry 156: 829-836.

Raichle ME, MacLeod AM, Snyder AZ, Powers WJ, Gusnard DA, Shulman GL (2001). A default mode of brain function. Proc Natl Acad Sci USA 98: 676-682. A seminal paper that introduced the concept of the default network, which refers to a stable pattern of organized brain activity that can be reliably detected when individuals are 'at rest', and that is interrupted during goal-directed behavior.

Ridderinkhof KR, Ullsperger M, Crone EA, Nieuwenhuis S (2004). The role of the medial frontal cortex in cognitive control. Science 296: 443-447.

Robertson B, Wang L, Diaz MT, Aiello M, Gersing K, Beyer J et al (2007). Effect of bupropion extended release on negative emotion processing in major depressive disorder: a pilot functional magnetic resonance imaging study. J Clin Psychiatry 68: 261-267

Rose EJ, Simonotto E, Ebmeier KP (2006). Limbic over-activity in depression during preserved performance on the n-back task. Neuroimage 29: 203-215.

Rosenthal R (1991). Meta-Analytic Procedures for Social Research. Sage: Beverly Hills, CA.

Salvadore G, Cornwell BR, Colon-Rosario V, Coppola R, Grillon C, Zarate Jr CA et al (2009). Increased anterior cingulate cortical activity in response to fearful faces: a neurophysiological biomarker that predicts rapid antidepressant response to ketamine. Biol Psychiatry 65: 289-295. This work demonstrated that increased rACC activation to fearful faces predicts a rapid antidepressant response to the $\mathbf{N}$-methyl-D-aspartate receptor antagonist ketamine.

Salvadore G, Cornwell BR, Sambataro F, Latov D, Colon-Rosario V, Carver F et al (2010). Anterior cingulate desynchronization and functional connectivity with the amygdala during a working memory task predict rapid antidepressant response to ketamine. Neuropsychopharmacology 35: 1415-1422.

Sanacora G, Zarate CA, Krystal JH, Manji HK (2008). Targeting the glutamatergic system to develop novel, improved therapeutics for mood disorders. Nat Rev Drug Discov 7: 426-437. A comprehensive review of the role of glutamate in the pathophysiology of depression and the mechanism of action of antidepressants

Sanders WA, Lam DH (2010). Ruminative and mindful self-focused processing modes and their impact on problem solving in dysphoric individuals. Behav Res Ther 48: 747-753.

Saxena S, Brody AL, Ho ML, Zohrabi N, Maidment KM, Baxter Jr LR (2003). Differential brain metabolic predictors of response to paroxetine in obsessive-compulsive disorder versus major depression. Am J Psychiatry 160 522-532.

Schlösser RG, Wagner G, Koch K, Dahnke R, Reichenbach JR, Sauer H (2008). Fronto-cingulate effective connectivity in major depression: a study with $\mathrm{fMRI}$ and dynamic causal modeling. Neuroimage 43: 645-655.

Schmitz TW, Johnson SC (2006). Self-appraisal decisions evoke dissociated dorsal-ventral aMPFC networks. Neuroimage 30: 1050-1058.

Schoning S, Zwitserlood P, Engelien A, Behnken A, Kugel H, Schiffbauer $\mathrm{H}$ et al (2009). Working-memory $\mathrm{fMRI}$ reveals cingulate hyperactivation in euthymic major depression. Hum Brain Mapp 30: 2746-2756.

Scott Al, Dougall N, Ross M, O'Carroll RE, Riddle W, Ebmeier KP et al (1994). Short-term effects of electroconvulsive treatment on the uptake of $99 \mathrm{mTc}$ exametazime into brain in major depression shown with single photon emission tomography. J Affect Disord 30: 27-34.

Segawa K, Azuma H, Sato K, Yasuda T, Arahata K, Otsuki K et al (2006). Regional cerebral blood flow changes in depression after electroconvulsive therapy. Psychiatry Res 147: 135-143.

Seminowicz DA, Mayberg HS, Mclntosh AR, Goldapple K, Kennedy S, Segal Z et al (2004). Limbic-frontal circuitry in major depression: a path modeling metanalysis. Neuroimage 22: 409-418. 
Shah PJ, O'Carroll RE, Rogers A, Moffoot AP, Ebmeier KP (1999). Abnormal response to negative feedback in depression. Psychol Med 29: 63-72.

Shallice T (1982). Specific impairments of planning. Philos Trans R Soc London B Biol Sci 298: 199-209.

Sheline YI, Barch DM, Price JL, Rundle MM, Vaishnavi SN, Snyder AZ et al (2009). The default mode network and self-referential processes in depression. Proc Natl Acad Sci USA 106: 1942-1947. Empirical demonstration that individuals with MDD are characterized by an inability to reduce activity in the default network, including the rACC, when they are either passively viewing or actively reappraising negative pictures.

Sheline YI, Price JL, Vaishnavi SN, Mintun MA, Barch DM, Epstein AA et al (2008). Regional white matter hyperintensity burden in automated segmentation distinguishes late-life depressed subjects from comparison subjects matched for vascular risk factors. Am J Psychiatry 165: 524-532.

Shimony JS, Sheline YI, D’Angelo G, Epstein AA, Benzinger TL, Mintun MA et al (2009). Diffuse microstructural abnormalities of normal-appearing white matter in late life depression: a diffusion tensor imaging study. Biol Psychiatry 66: 245-252.

Shulman GL, Fiez JA, Corbetta M, Buckner RL, Miezin FM, Raichle ME et al (1997). Common blood flow changes across visual tasks: II. Decreases in cerebral cortex. J Cog Neurosci 9: 648-663.

Siegle GJ, Carter CS, Thase ME (2006). Use of FMRI to predict recovery from unipolar depression with cognitive behavior therapy. Am J Psychiatry 163: 735-738.

Siegle GJ, Thompson W, Carter CS, Steinhauer SR, Thase ME (2007). Increased amygdala and decreased dorsolateral prefrontal BOLD responses in unipolar depression: related and independent features. Biol Psychiatry 61: 198-209.

Simoes-Franklin C, Hester R, Shpaner M, Foxe JJ, Garavan H (2010). Executive function and error detection: the effect of motivation on cingulate and ventral striatum activity. Hum Brain Mapp 31: 458-469.

Simpson Jr JR, Snyder AZ, Guznard DA, Raichle ME (2001). Emotion-induced changes in human medial prefrontal cortex: I. During cognitive task performance.. Proc Natl Acad Sci USA 98: 683-687.

Smith DJ, Muir WJ, Blackwood DH (2006). Neurocognitive impairment in euthymic young adults with bipolar spectrum disorder and recurrent major depressive disorder. Bipolar Disord 8: 40-46.

Smith EE, Jonides J (1999). Storage and executive processes in the frontal lobes. Science 283: 1657-1661.

Smith GS, Reynolds III CF, Houck PR, Dew MA, Ginsberg J, Ma Y et al (2009). Cerebral glucose metabolic response to combined total sleep deprivation and antidepressant treatment in geriatric depression: a randomized, placebocontrolled study. Psychiatry Res 171: 1-9.

Smith GS, Reynolds III CF, Houck PR, Dew MA, Ma Y, Mulsant BH et al (2002). Glucose metabolic response to total sleep deprivation, recovery sleep, and acute antidepressant treatment as functional neuroanatomic correlates of treatment outcome in geriatric depression. Am J Geriatr Psychiatry 10: 561-567.

Smith GS, Reynolds III CF, Pollock B, Derbyshire S, Nofzinger E, Dew MA et al (1999). Cerebral glucose metabolic response to combined total sleep deprivation and antidepressant treatment in geriatric depression. Am J Psychiatry 156: 683-689.

Sneed JR, Roose SP, Keilp JG, Krishnan KR, Alexopoulos GS, Sackeim HA (2007). Response inhibition predicts poor antidepressant treatment response in very old depressed patients. Am J Geriatr Psychiatry 15: 553-563.

Sounuga-Barke EJ, Castellanos FX (2007). Spontaneous attentional fluctuations in impaired states and pathological conditions: a neurobiological hypothesis. Neurosci Biobehav Rev 31: 977-986.

Speer AM, Benson BE, Kimbrell TK, Wassermann EM, Willis MW, Herscovitch P et al (2009). Opposite effects of high and low frequency rTMS on mood in depressed patients: relationship to baseline cerebral activity on PET. $J$ Affect Disord 115: 386-394.

Steffens DC, Wagner HR, Levy RM, Horn KA, Krishnan KR (2001). Performance feedback deficit in geriatric depression. Biol Psychiatry 50: 358-363.

Sweeney JA, Kmiec JA, Kupfer DJ (2000). Neuropsychologic impairments in bipolar and unipolar mood disorders on the CANTAB neurocognitive battery. Biol Psychiatry 48: 674-684.

Talbot PS, Cooper SJ (2006). Anterior cingulate and subgenual prefrontal blood flow changes following tryptophan depletion in healthy males. Neuropsychopharmacology 31: 1757-1767.

Tang Y, Wang F, Xie G, Liu J, Li L, Su L et al (2007). Reduced ventral anterior cingulate and amygdala volumes in medication-naive females with major depressive disorder: a voxel-based morphometric magnetic resonance imaging study. Psychiatry Res 156: 83-86.

Taylor SF, Martis B, Fitzgerald KD, Welsh RC, Abelson JL, Liberzon I et al (2006). Medial frontal cortex activity and loss-related responses to errors. J Neurosci $\mathbf{2 6}$ : 4063-4070.
Taylor Tavares JV, Clark L, Cannon DM, Erickson K, Drevets WC, Sahakian BJ (2007). Distinct profiles of neurocognitive function in unmedicated unipolar depression and bipolar II depression. Biol Psychiatry 62: 917-924.

Taylor Tavares JV, Clark L, Furey ML, Williams GB, Sahakian BJ, Drevets WC (2008). Neural basis of abnormal response to negative feedback in unmedicated mood disorders. Neuroimage 42: 1118-1126.

Taylor WD, Kuchibhatla M, Payne ME, Macfall JR, Sheline YI, Krishnan KR et al (2008). Frontal white matter anisotropy and antidepressant remission in late-life depression. PLoS One 3: e3267.

Taylor WD, MacFall JR, Payne ME, McQuoid DR, Provenzale JM, Steffens DC et al (2004). Late-life depression and microstructural abnormalities in dorsolateral prefrontal cortex white matter. Am J Psychiatry 161: 1293-1296.

Teasdale JD (1999). Emotional processing, three modes of mind and the prevention of relapse in depression. Behav Res Ther 37(Suppl 1): S53-S77.

Tekin S, Cummings JL (2002). Frontal-subcortical neuronal circuits and clinical neuropsychiatry: an update. J Psychosom Res 53: 647-654.

Teneback CC, Nahas Z, Speer AM, Molloy M, Stallings LE, Spicer KM et al (1999). Changes in prefrontal cortex and paralimbic activity in depression following two weeks of daily left prefrontal TMS. J Neuropsychiatry Clin Neurosci 11: 426-435.

Tomasi D, Ernst T, Caparelli EC, Chang L (2006). Common deactivation patterns during working memory and visual attention tasks: an intra-subject fMRI study at 4 Tesla. Hum Brain Mapp 27: 694-705.

Treadway MT, Grant MM, Ding Z, Hollon SD, Gore JC, Shelton RC (2009). Early adverse events, HPA activity and rostral anterior cingulate volume in MDD. PLoS One 4: e4887.

Treynor W, Gonzales R, Noel-Hoeksema S (2003). Rumination reconsidered: a psychometric analysis. Cognitive Ther Res 27: 247-259. A study showing that rumination can be decomposed into adaptive (eg, reflective pondering) and maladaptive (eg, brooding) components, which predicted lower and higher levels of depressive symptoms 1 year later, respectively.

Trichard C, Martinot JL, Alagille M, Masure MC, Hardy P, Ginestet D et al (1995). Time course of prefrontal lobe dysfunction in severely depressed in-patients: a longitudinal neuropsychological study. Psychol Med 25: 79-85.

Trivedi MH, Rush AJ, Wisniewski SR, Nierenberg AA, Warden D, Ritz L et al (2006). Evaluation of outcomes with citalopram for depression using measurementbased care in STAR*D: implications for clinical practice. Am J Psychiatry 163: 28-40.

van Buuren M, Gladwin TE, Zandbelt BB, Kahn RS, Vink M (2010). Reduced functional coupling in the default-mode network during self-referential processing. Hum Brain Mapp 31: 1117-1127.

Van Dijk KR, Hedden T, Venkataraman A, Evans KC, Lazar SW, Buckner RL (2010). Intrinsic functional connectivity as a tool for human connectomics: theory, properties, and optimization. J Neurophysiol 103: 297-321.

Van Veen V, Carter CS (2006). Conflict and cognitive control in the brain. Curr Dir Psychol Sci 15: 237-240.

Vasic N, Walter H, Hose A, Wolf RC (2008). Gray matter reduction associated with psychopathology and cognitive dysfunction in unipolar depression: a voxelbased morphometry study. J Affect Disord 109: 107-116.

Vasic N, Walter H, Sambataro F, Wolf RC (2009). Aberrant functional connectivity of dorsolateral prefrontal and cingulate networks in patients with major depression during working memory processing. Psychol Med 39: 977-987.

Vlassenko A, Sheline YI, Fischer K, Mintun MA (2004). Cerebral perfusion response to successful treatment of depression with different serotoninergic agents. J Neuropsychiatry Clin Neurosci 16: 360-363.

Vogt BA, Nimchinsky EA, Vogt LJ, Hof PR (1995). Human cingulate cortex: surface features, flat maps, and cytoarchitecture. J Comp Neurol 359: 490-506.

Vogt BA, Vogt L, Farber NB, Bush G (2005). Architecture and neurocytology of monkey cingulate gyrus. J Comp Neurol 485: 218-239.

Volk SA, Kaendler SH, Hertel A, Maul FD, Manoocheri R, Weber R et al (1997). Can response to partial sleep deprivation in depressed patients be predicted by regional changes of cerebral blood flow? Psychiatry Res 75: 67-74.

Vul E, Harris C, Winkielman P, Pashler H (2009). Puzzlingly high correlations in fMRI studies of emotion, personality, and social cognition. Perspect Psychol Sci 4: 274-290.

Wagner G, Sinsel E, Sobanski T, Kohler S, Marinou V, Mentzel HJ et al (2006). Cortical inefficiency in patients with unipolar depression: an event-related FMRI study with the Stroop task. Biol Psychiatry 59: 958-965.

Walter H, Wolf RC, Spitzer M, Vasic N (2007). Increased left prefrontal activation in patients with unipolar depression: an event-related, parametric, performancecontrolled fMRI study. J Affect Disord 101: 175-185.

Walter M, Henning A, Grimm S, Schulte RF, Beck J, Dydak U et al (2009). The relationship between aberrant neuronal activation in the pregenual anterior cingulate, altered glutamatergic metabolism, and anhedonia in major depression. Arch Gen Psychiatry 66: 478-486. The first study to show that task-related deactivation of the rACC during an emotional task correlated with rACC glutamate level in individuals with MDD, but not in controls. 
Wang L, Krishnan KR, Steffens DC, Potter GG, Dolcos F, McCarthy G (2008a). Depressive state- and disease-related alterations in neural responses to affective and executive challenges in geriatric depression. Am J Psychiatry 165: 863-871.

Wang L, LaBar KS, Smoski M, Rosenthal MZ, Dolcos F, Lynch TR et al (2008b). Prefrontal mechanisms for executive control over emotional distraction are altered in major depression. Psychiatry Res 163: 143-155.

Watkins ER (2008). Constructive and unconstructive repetitive thought. Psychol Bull 134: 163-206.

Watkins E, Brown RG (2002). Rumination and executive function in depression: an experimental study. J Neurol Neurosurg Psychiatry 72: 400-402. One of the first experimental studies showing that induced rumination leads to reduced inhibitory executive control in depressed participants.

Watkins E, Teasdale JD (2004). Adaptive and maladaptive self-focus in depression. $J$ Affect Disord 82: 1-8.

Weiland-Fiedler P, Erickson K, Waldeck T, Luckenbaugh DA, Pike D, Bonne O et al (2004). Evidence for continuing neuropsychological impairments in depression. J Affect Disord 82: 253-258.

Weissman DH, Roberts KC, Visscher KM, Woldorff MG (2006). The neural bases of momentary lapses in attention. Nat Neurosci 9: 971-978.

Wenzlaff RM, Grozier SA (1988). Depression and the magnification of failure. J Abnorm Psychol 97: 90-93.

Wilson SM, Molnar-Szakacs I, lacoboni M (2008). Beyond superior temporal cortex: intersubject correlations in narrative speech comprehension. Cereb Cortex 18: 230-242.
Wolf FM (1986). Meta-Analysis: Quantitative Methods for Research Synthesis. Sage Publications, Inc.: Newbury Park, CA.

World Health Organization (WHO) (2008). The Global Burden of Disease: 2004 Update (PDF). WHO Press: Geneva, Switzerland.

Wu J, Buchsbaum MS, Gillin JC, Tang C, Cadwell S, Wiegand M et al (1999). Prediction of antidepressant effects of sleep deprivation by metabolic rates in the ventral anterior cingulate and medial prefrontal cortex. Am J Psychiatry 156: 1149-1158.

Wu JC, Gillin JC, Buchsbaum MS, Hershey T, Johnson JC, Bunney Jr WE (1992). Effect of sleep deprivation on brain metabolism of depressed patients. Am J Psychiatry 149: 538-543.

Yoshimura S, Okamoto Y, Onoda K, Matsunaga M, Ueda K, Suzuki S et al (2010). Rostral anterior cingulate cortex activity mediates the relationship between the depressive symptoms and the medial prefrontal cortex activity. $J$ Affect Disord 122: $76-85$.

Yoshimura S, Ueda K, Suzuki S, Onoda K, Okamoto Y, Yamawaki S (2009). Selfreferential processing of negative stimuli within the ventral anterior cingulate gyrus and right amygdala. Brain Cogn 69: 218-225.

Yuan Y, Zhu W, Zhang Z, Bai F, Yu H, Shi Y et al (2008). Regional gray matter changes are associated with cognitive deficits in remitted geriatric depression: an optimized voxel-based morphometry study. Biol Psychiatry 64: 541-544.

Zhang TJ, Wu QZ, Huang XQ, Sun XL, Zou K, Lui S et al (2009). Magnetization transfer imaging reveals the brain deficit in patients with treatment-refractory depression. J Affect Disord 117: 157-161. 